أثر استخدام برنامجين للتدريب الفتري في القدرة اللاهو ائية ومعدل التنفس و النبض بعد الجهد وفي فترة الاستشفاء لدى لاعبي كرة القدم

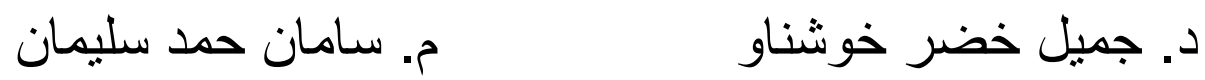
جامعة صلاح الدين / كلية التربية الرياضية

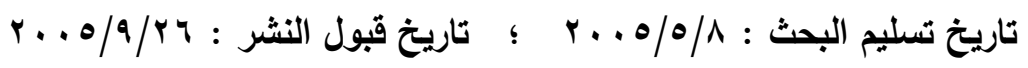

ملخص البحث: : 20

يهـدف البحث الى معرفـة تأثثر استخدام تدريبات فتريـة متتوعـة على تطوير القدرة اللاهوائية ومعدل سرعة النبض وعدد مرات التنفس في فترة الاستثفاء. تكونت عينة البحث من مجموعتين تجريبيتين متكافئتين من شباب نادي اربيل الرياضي

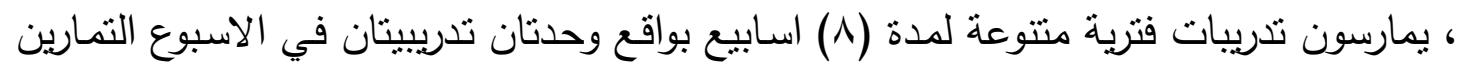

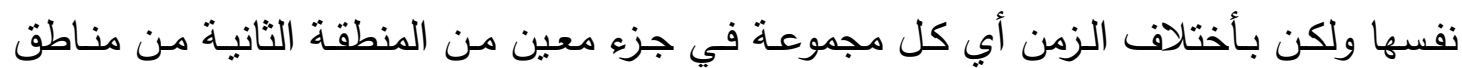
التدريب الفتري المعتمد على الزمن.

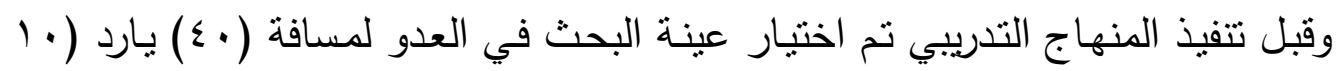

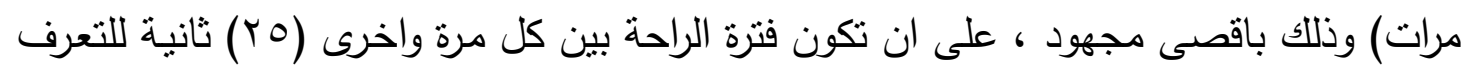

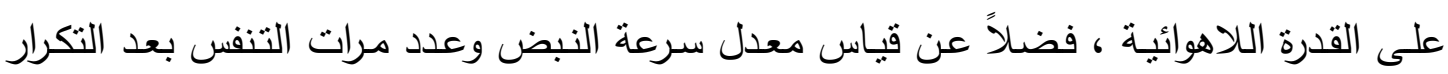
العاشر مباشرة ،وفي خـلال دقيقتين تم قياس معدل سرعة النبض في الدقيقة الاولى و الثانية

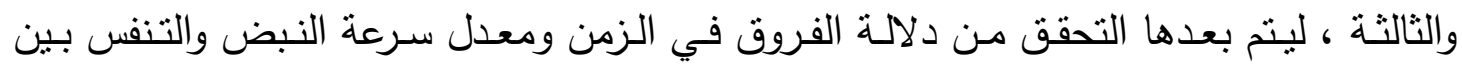

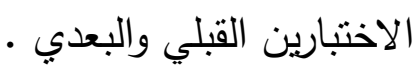

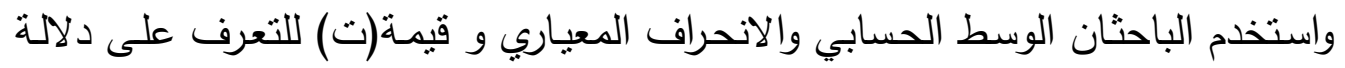

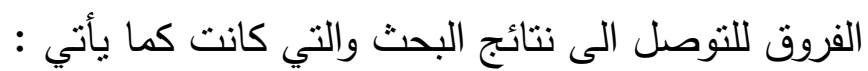

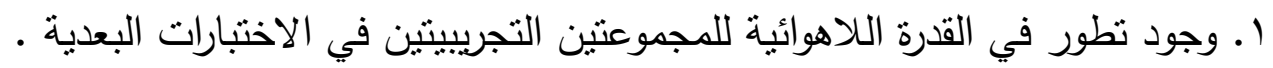

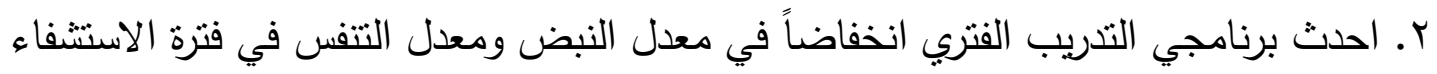

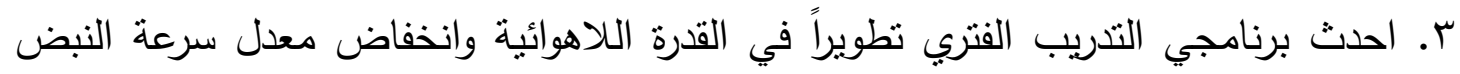
وعدد مرات التنفس لاى عينة البحث الثانية بشكل أكبر. اما اهم التوصيات التي اوصى بها الباحثان كانت كما يأني : 
ا. ضرورة استخدام تدريبات فترية متتوعة في تدريب كرة القدم للتأثير الايجابي لهذه التدريبات

$$
\text { في تطوير القدرة اللاهوائية . }
$$

r. التاكيد على مدربي كرة القدم الاعتماد على القياسات الوظيفية ومنها معدل ضربات القلب

والتنفس عند وضع البرامج التدريبية لينسنى لهم وضع الحمل التدريبي المناسب للوحدات

r. التأكيد على مدربي كرة القدم بتتظيم الحمل التدريبي عند وضع برامج التدريبية على وفق التق انظمة انتاج طاقة المرتبطة بالفعالية .

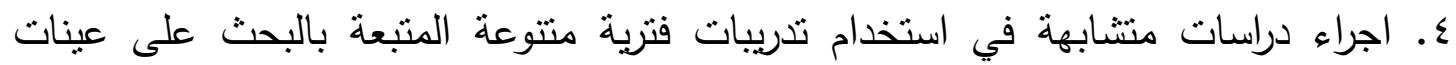

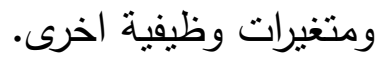

\section{Effect of using two deferent interval training To develop Anaerobic Power and pulse rate average, and some respiratory frequency during Recovery for foot ball players}

\section{Dr. Jammil K. Koshnaw Samman H. Soleman \\ University of Slahaldeen - College of Sport Education}

\section{Abstract:}

The aim of Research : To know the Effect using two deferent interval training to develop Anaerobic, pulse rate average and the some respiratory frequency during the Recovery .

The Sample of Research included using Two experimental groups Aril Club youth .

These Two group are training deferent interval training for 8 weeks two unite training in a week the same exercises but there is deferments time between the each group training in the part appointed in part two in interval districts in inter volt training depending times .

Before performance the program training .

The sample Research Selected in 40 yard running 10 times in maximum of ability . 
There are 25 Second between each running to know anaerobic power.

After two minutes The rate pulse was measured in the first minute - two minute - third minute after that in retargeted the differences in times and the average of pulse rate in recovery and Respiratory between pre- tests and post - tests .

The Researcher was using mean stander deviation and (Attest) to notify significant deferent's in order to get The results :

1. There is development of both experimental groups in post tests.

2. The two interval training period (8) weeks showed in the average of pulse rate in parliamentary and in average aspiratory.

3. The two interval training various different period of $(8)$ weeks developed in anaerobic power in the the rate pulse speed and the number Respiratory for the sample number two more the first sample.

The important Recommendations are following :

1. it is necessary to use the deferent interval training exercise in foot ball for positive effect for these exercises to develop in anaerobic .

2. To emphases on foot ball coaches to account on measurement physiological such as average of pulse rate an Respiratory in planning training program of load training suitable to the unites.

3. To emphases on the trainers foot ball to different interval organize the load training in training program putting in the producers energy .

4. To do more the studies and using various different interval training exercise on another sample and on the some physiological variables. 
يعد السعي لتحقيق المستويات الرياضية العالية لانواع الانشطة والفعاليات الرياضية

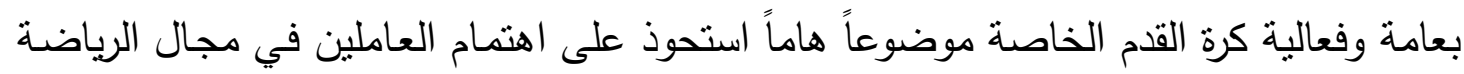

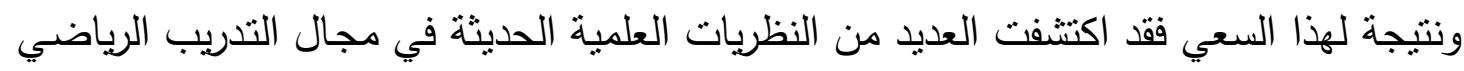
والتي ادت الى تفسير كثير من الظواهر وساعدت على ايجاد افضل الحلول لكثير من المشاكل

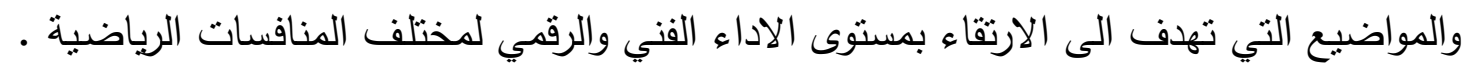

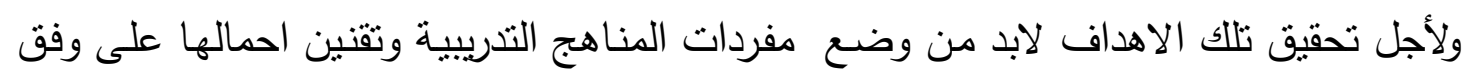
صيغ علمية بما بتتاسب مع قدرات اللاعبين.

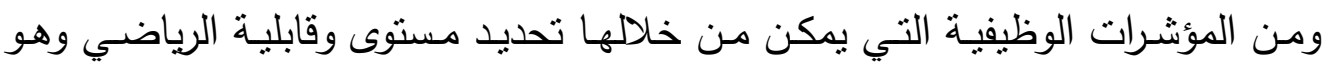
معدل النبض وعدد مرات التتفس : اذ يعد معدل ضربات القلب من المؤشرات التي تعتمد عليها

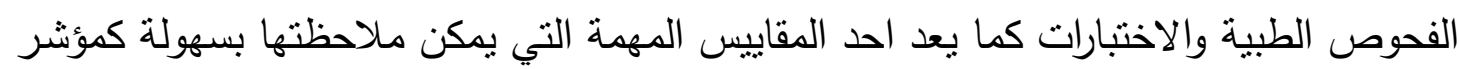

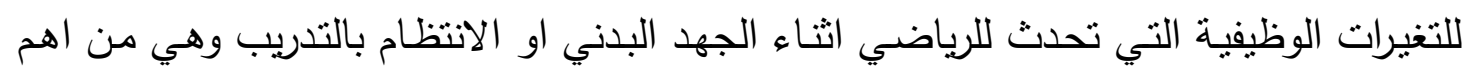

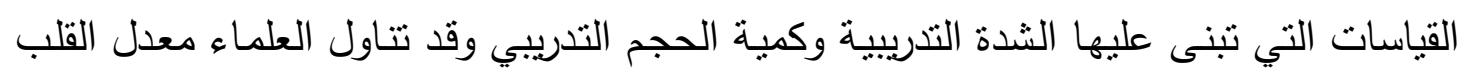
لاى الرياضي في بحوث كثيرة وعديدة وفي ضوئها وضعوا اسس الثدة وتقسيماتها من حيث

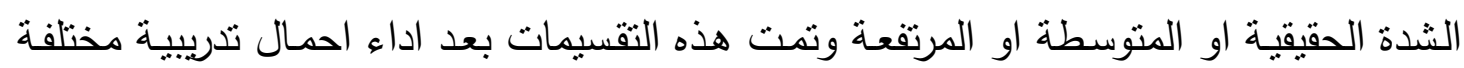

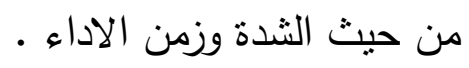
ويتاثر معدل ضربات القلب بعوامل عدة منها (الجنس - العمر - الحالة الانفعالية)

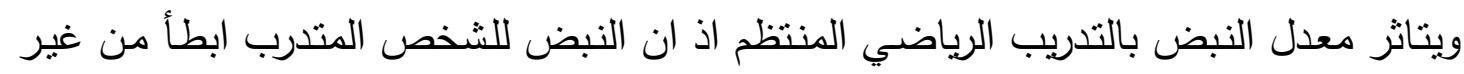

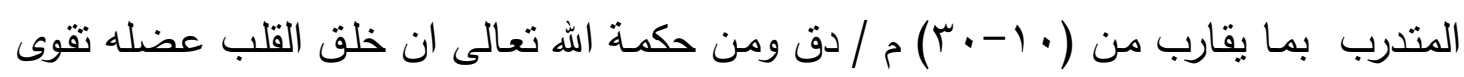

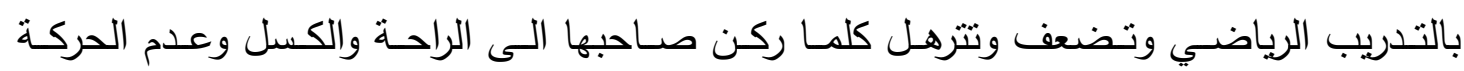
$(0: Y, T)$

ويشير الكيلاني ان وجود عاملين في عملية التدريب يؤثران في معدل القلب هما :

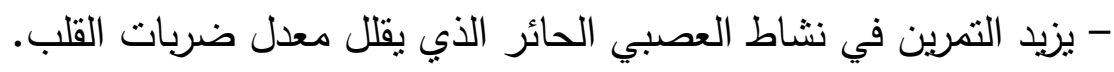

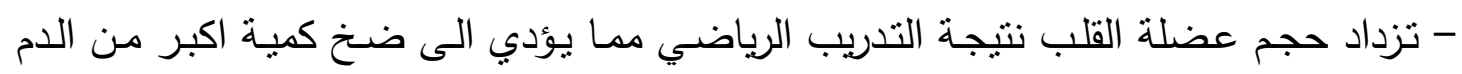

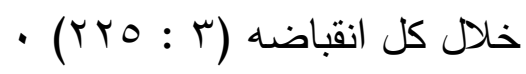
واوضحت الدراسـة التي قام بها (Bucher) ان الانتظام في التدريب العملي يضفي على الجسم بعض التكيفات الوظيفية التي تخفض معدل النبض وتزيد كفايـة العضلة القلبية $\cdot(0: 11)$ 
ومن المؤشرات الوظيفية الاخرى التي يمكن من خلالها تحديد مستوى وقابلية الرياضي

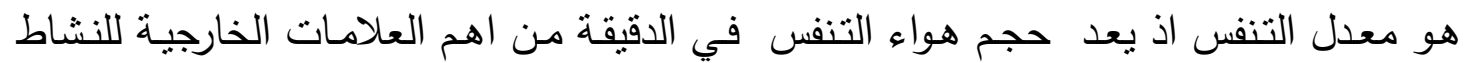
الرياضي وتصبح كمية الهواء المستنشق الذي يتتفسه الرياضي في اثتاء اداء الدجهود الرياضي

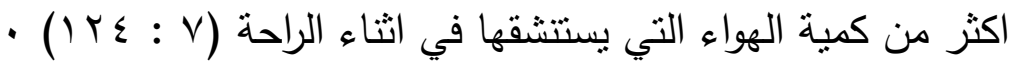
وقد اشار (Mcardle et. al.) "ان معدل التتفس هو احد المتغيرين الاساسيين في زيادة

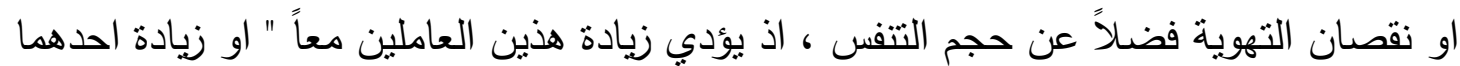

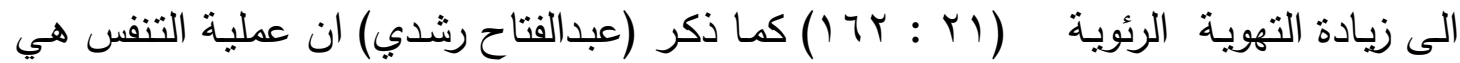

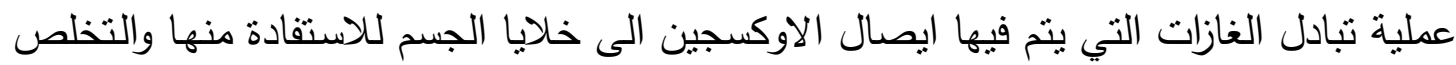

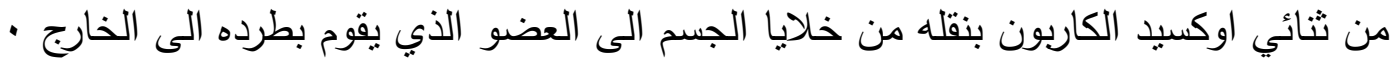

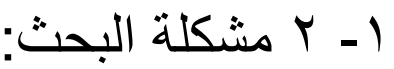

لقد اصبحت المعلومات الوظيفية والحقائق العلمية المستخلصة منها تشكل الاسس التي يعتمد عليها اغلبية الددربين لتحقيق الاهداف العلمية التدريبية . من المعروف ان العديد من الانشطة الرياضية و البدنية ومن ضمنها كرة القدم كثير من

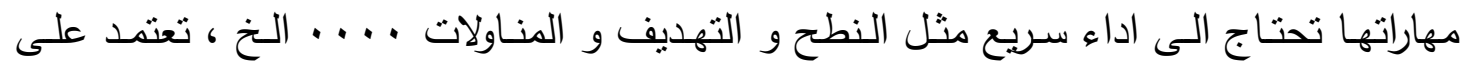
مـصادر الطاقـة الللاهوائيـة الناتجـة مـن تحلـل الـروابط الكيميائيـة لثنلاتثي فوسفات الادينـوزين (ATP) و فوسفات كرياتين (CP) ، كلايكوجين العضلة ، ذلك ان الاعمال البننية اللاهوائية لا لادئل

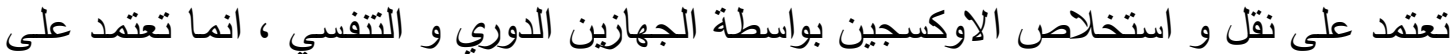
مصادر الطاقة الموجودة في داخل العضلة • ومن الظواهر التي يتعرض لها لاعبي كرة القدم هي انخفاض القدرة اللاهوائية لدى اغلبية لاعبي كرة القدم وهذه الظاهرة تؤدي الى التراجع السلبي في مستوى اللياقة البدنية والاداء

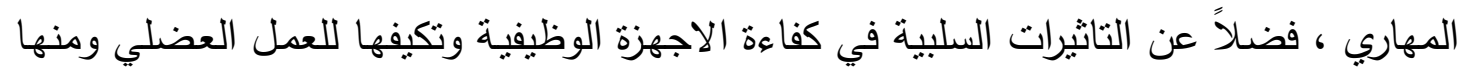

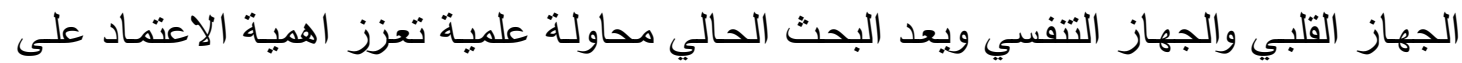
الاسس الوظيفية في التدريب الرياضي والوقوف على اهمية استخدام برنامجين بالتدريب الفتري

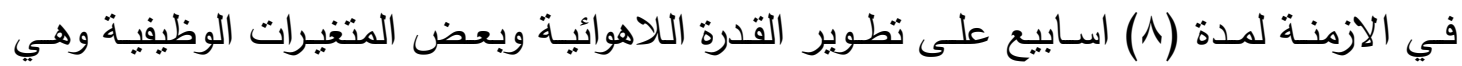
انخفاض معدل سرعة النبض والتنفس في فترة الاستثفاء . 
r-1-1 الكشف عن اثر استخدام برنـامجين بالتدريب الفتري على تطوير القدرة اللاهوائيـة

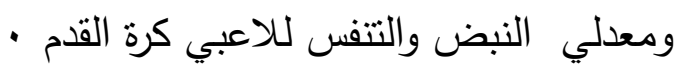

r-1-r الكثف عن دلالة الفروق في القدرة اللاهوائية ومعدلي النبض و التبف التفس للاعبي كرة القدم بين مجموعتي البحث في الاختبار البعدي.

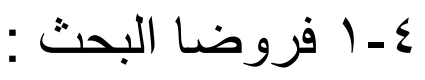

ـ - 1- ا وجود فروق ذات دلالة معنوية في القدرة اللاهوائية و معدلي النبض والتنفس للاعبي

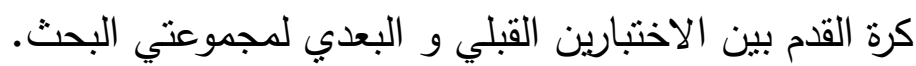

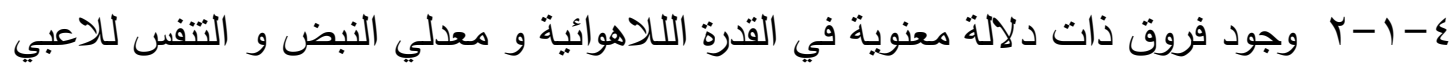
كرة القدم بين مجموعتي البحث في الاختبار البعدية.

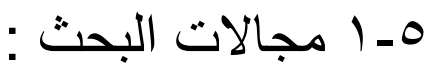
0-1-1الهجال البشري : لاعبي كرة القدم الشباب

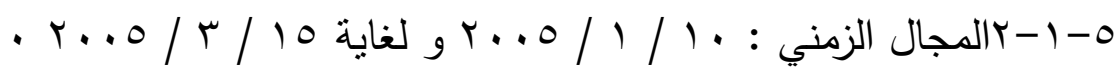

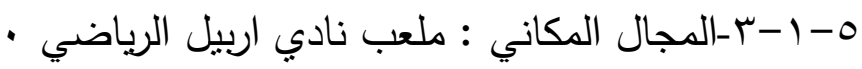

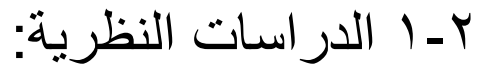

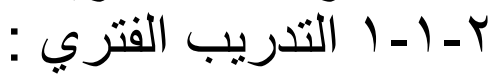

تعد طريقة التدريب الفتري أو طريقة التدريب على مراحل من الطرائق الرئيسة المهيدة

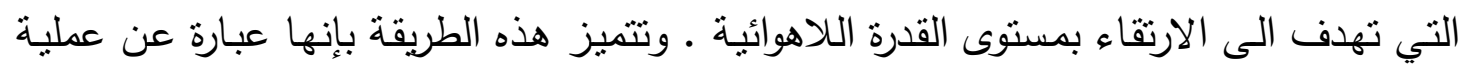
تبادل منتظم ومستمر بين العمل والراحة غير الكاملة ، ويراعي في حالة استخدام هذه الطريقة

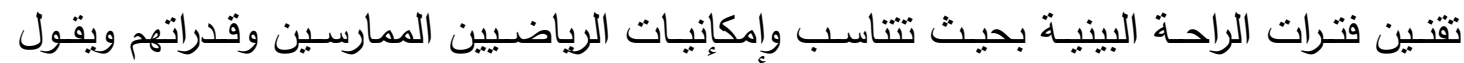

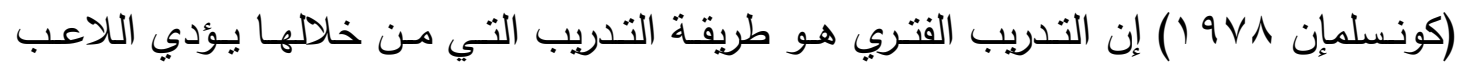

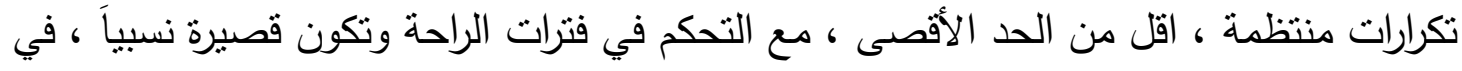

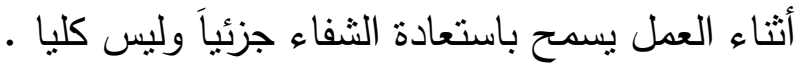

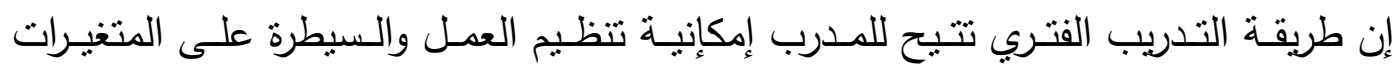

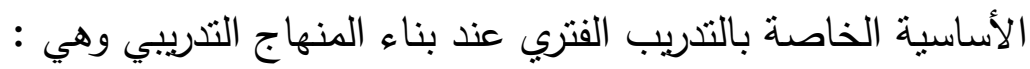

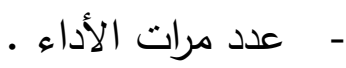

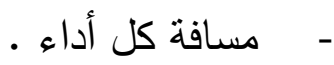

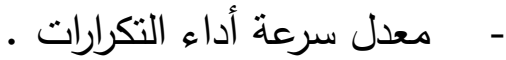

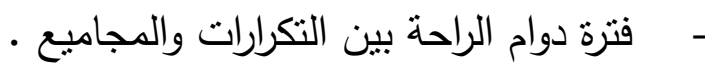

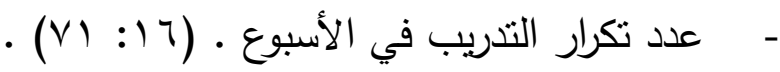


مـن المعروف إن العديد مـن الأنشطة الرياضية والبدنية تعتمد على مصادر الطاقة

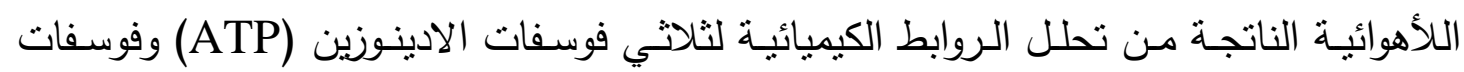

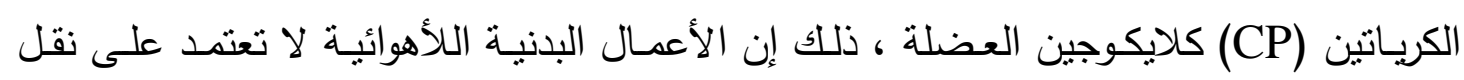
واستخلاص الأوكسجين بواسطة الجهازين الدوري والتنفسي ، و إنما تعتمد على مصادر الطاقة الطينة

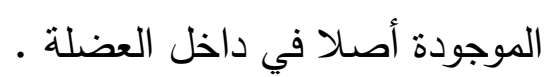
وتشمل الأنشطة اللأهوائية على مسابقات مثل العدو والسباحة والمصارعة وفعاليات الوثب وكذلك في الألعاب الفرقية عند أداء جميع المهارات التي تحتاج الى أداء سريع ووثب مثل

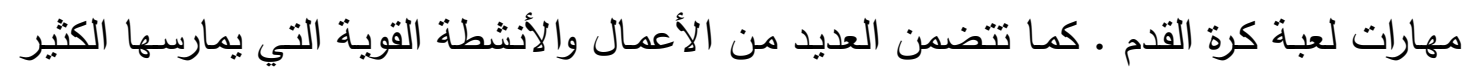

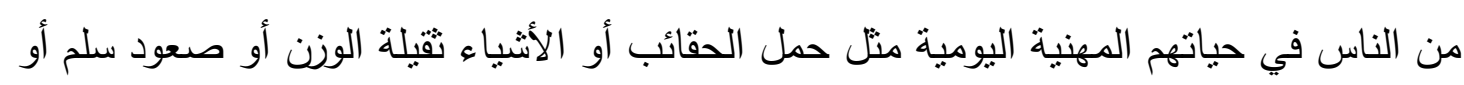

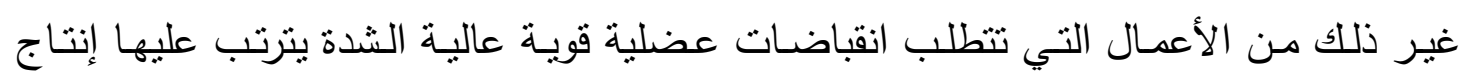
معدلات عالية من الطاقة في فترات زمنية قصيرة نسبياً . ويمكن تعرف القدرة اللأهوائية على " إنها أعلى معدل يحدث فئل عند إنتاج الطاقة أو الثغل

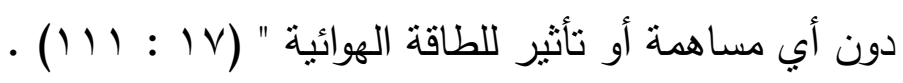

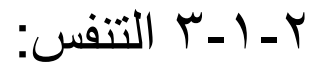
وتلعب العضلات التتفسية دوراً رئيسياً في تسهيل دخول وخروج الهواء الى الرئتين ، اذ ان عمليـة التنفس عمليـة لاراديـة يسيطر عليها الجهاز العصبي عن طريق مراكز عصبية موجودة في بعض اجزاء الدماغ النخاع المستطيل (Medulla oblongta) والجسر (pons) وهذه المراكز هي المركز الشهيقي والمركز الزفيري ومركز الابيونوستلك ومركز النيوموتاكسك

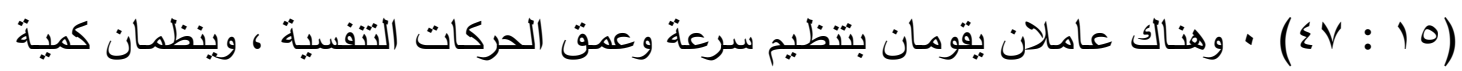
الاوكسجين التي تصل الى الخلايا وسرعة تخليص الخلايا من ثنائي اوكسيد الكاربون ، وهذان العـاملان هـا التحكم العصبي (Nervous Contre) والتحكم الكيميائي ( Chemical $\cdot(r \cdot r: \tau)($ Contnel ويؤكد (Guyton) ان عملية التدريب الرياضـي تحدث للرياضسي تكيفات في الجهاز التنفسي مما يؤدي الى انخفاض معدل التتفسي نتيجة لقوة عضلات الصدر مما يؤدي الى زيادة

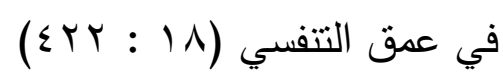


ان مستوى الرياضي عالمياً على وجه التحديد في كرة القدم في السنوات الاخيرة بصورة لم يسبق له مثيل من قبل ، وقد يعزى قبل كل شيء الى استخدام الخطط والطرائق التدرييية المختلفة والمبرمجة والتي تعمل على تحقيق الهدف التدريبي بصورة صحيحة ومدروسة ، ومن لهن هذه الطرائق هي طريقة التدريب الفتري باساليبها المتعددة التي يمكن من خلالها تطوير انظمة

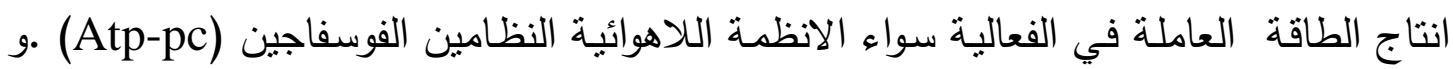
• نظام حامض اللبنيك (LA) ومن خلال ما سبق ذكره آنفاً تبرز اهمية البحث في معرفة الحقائق العلمية لاثر استخدام

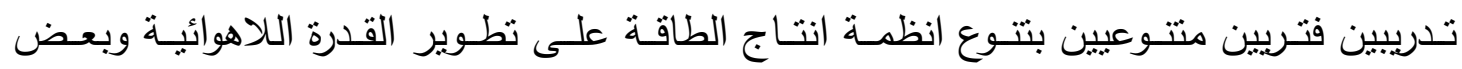
المتغيرات الوظيفية التي تحدث في معدل النبض وعدد مرات التنفس في فترة الاستشفاء والتي يمكن من خلالها الوصول الى المعلومات او المؤشرات التي يستفاد منها في عملية بناء وتخطيط

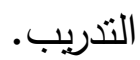

r - ا ـ ـ فو ائد استخدام النبض في التدريب الرياضي :

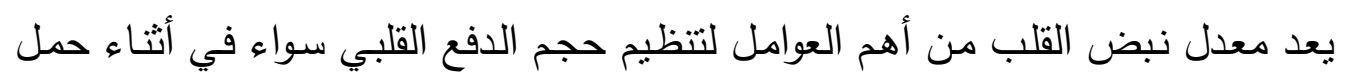
البدني ذب الثدة المنخفضة أم الثدة المرتفعة ، وقد تمت دراسة معدل النبض عند أداء مختلف لهن الأحمال البدنية من حيث الثدة وزمن الأداء ، وتوجد هنالك علاقة مباشرة بين شكل الجهد البدني ومعدل النبض وشدة التنريبات التي يقوم اللاعب بأدائها ، لذا يزداد النبض نتيجة للمجهود الذي لهي

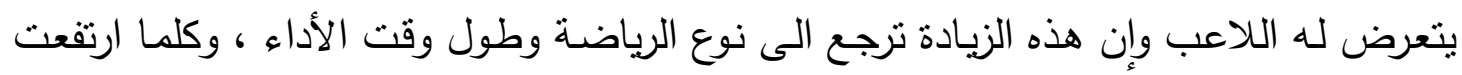
كفاءة الفرد البدنية انخفض معدل النبض وهذا يظهر ميزة القلب الرياضي إذ إنه لا يعطي إنتاجا

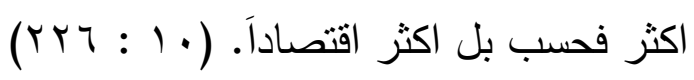
إن قياس معدل نبضات القلب يمكن استخدامه في تحديد نظام الطاقة الذي يستخدمه الرياضيون في التمرين ومستوى شدة التدريب وكثافته ووقت الاستشفاء بين التمارين ومسنتى الإعياء الرياضي ، ونتيجة لذلك يعد قياس معدل النبض أحد الأدوات الأكثر أهمية والمتوافرة

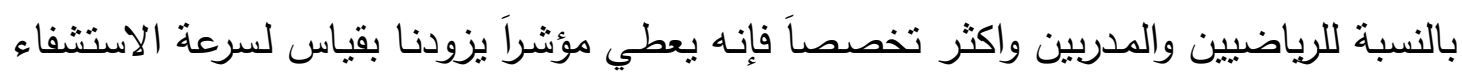
بين التكرارات ويساعد في منع ظاهرة الحمل الزائد عندما لا ينم الاستشفاء لرياضي بصورة جيدة

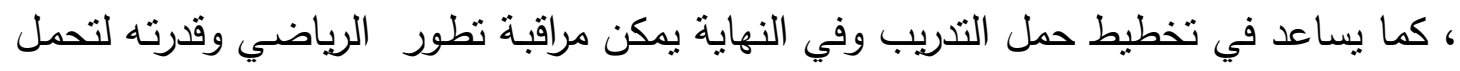
الحمل العالي للعمل (ع ب: 09 09). 
Y ـ ا ــ فترة استعادة الثفاء بعد التمرين :

بعد هذا الموضوع من المواضيع المهمة جداً في مجال الرياضي ، نظرا لفوائده التطبيقية إذ لا يمكن الاستغناء عنه أثناء التدريب إذ تدعي فترة الراحة التي تعقب التمرين مباشرة (بفترة استعادة الثفاء) ، وهي الفترة التي يعوض فيها الفرد عجزه الأوكسجيني ، ويحدد مقدار الدين

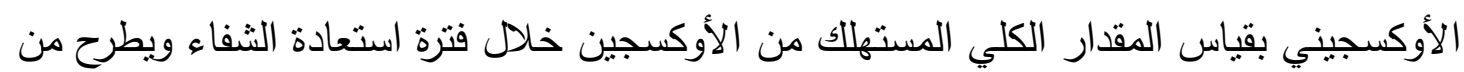

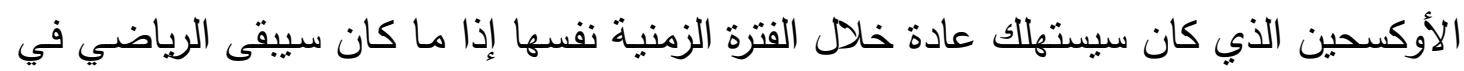

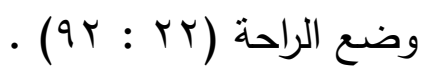

من المعروف إنه بعد الانتهاء من التمرين تكون حاجتتا للطاقة اقل بكثير وذلك لأننا سوف نتوقف عن التدريب على رغم من إن استهلاكنا للأوكسجين يستمر عند مستوى عالي نسبيا لفترة من الزمن وذللك للعودة بالمتغيرات الفسلجية مثل معدل نبضات القلب والناتج القلبي ودرجة حرارة الجسم وغيرها من المتغيرات الى مستوياتها نفسها التي كانت عليها في أثناء فترة

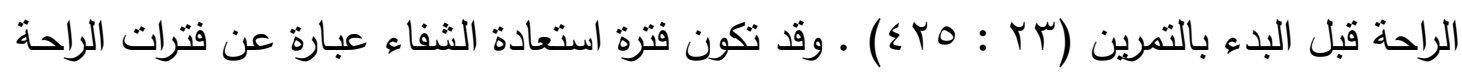

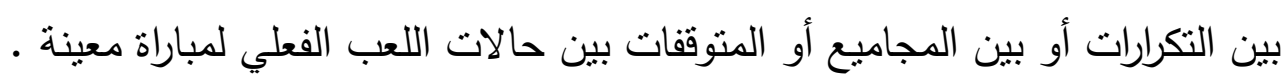
وتحاول أجهزة الجسم في أثناء هذه الفترة وكذلك أنظمة الطاقة العملة وأنظمة التوصيل

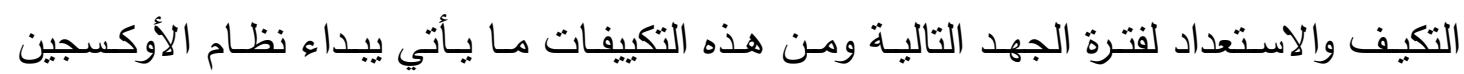
بتعويض العجز الأوكسجيني الناتج عن التمرين فهو يعيد خزن نظام الطاقة (ATP -PC) . (IV: $Y \varepsilon)$

ولغرض زيادة سرعة الاستشفاء هناك نوعان من الراحة بعد التمرين وهي : - الراحة السلبية : وهي الفترة التي يستريح فيها الرياضـي من التمرين أو يؤدي فيها تمرينات مشي أو تمارين تمطية . - الراحة الإيجابية :

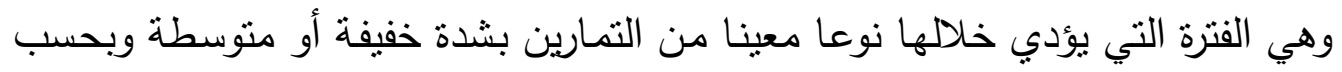

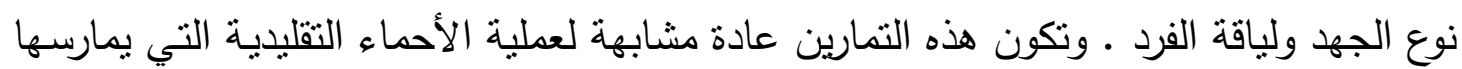

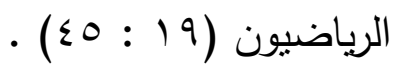

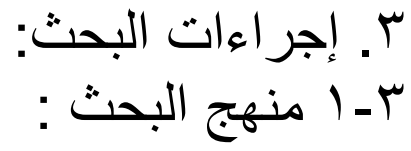


استخدم الباحثان المنهج التجريبي لملائمته لطبيعة المشكلة فالمنهج التجريبي يقوم على الفى الفي

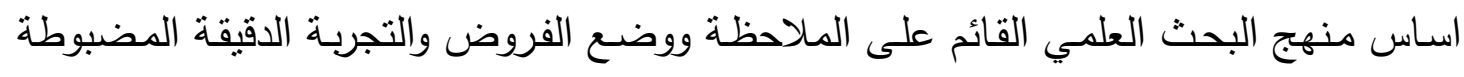

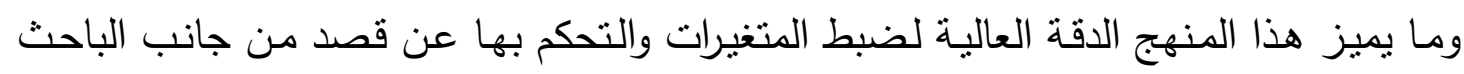
. (ابراهيم : (1910)

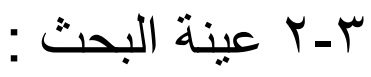

تم اجراء البحث على عينة من لاعبي شباب نادي اربيل الرياضي بعمر دون (9 (1) سنة

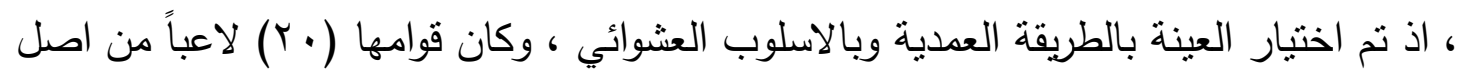

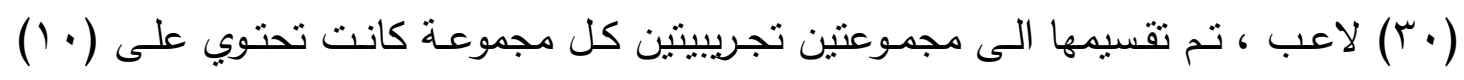
لاعبين يمارسون نفس التمارين بنفس الوقت ، أي كل مجموعة في جزء معين من منطقة الثانية

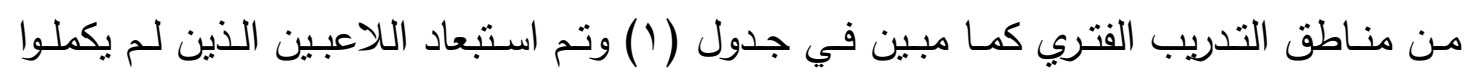

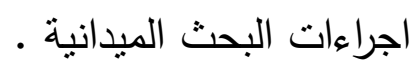

جدول (1)

دليل بناء منهاج التدريب الفتري المعتمد على زمن المنطقة الثانية

\begin{tabular}{|c|c|c|c|c|c|c|c|}
\hline$\tau$ & j & و و & هـ & د & ج & ب & i \\
\hline نهع الرادة & النى الرادة العل & الدجمع الكرارات في & علد التوحدة: & الودات التكترات فيبية & زقد التكريب & نظام الطاقة & منطقة العطل \\
\hline \multirow{2}{*}{ راجية } & \multirow[t]{2}{*}{$(1: r)$} & 0 & 0 & ro & ث. • & $\begin{array}{c}\text { ATP-PC } \\
+ \text { LA }\end{array}$ & r \\
\hline & & 。 & $\varepsilon$ & r. & ث/0.- & & \\
\hline
\end{tabular}

$(0 .: 19)$

ب- ت تكافؤ مجمو عتي البحث :

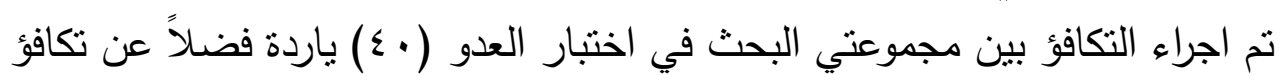

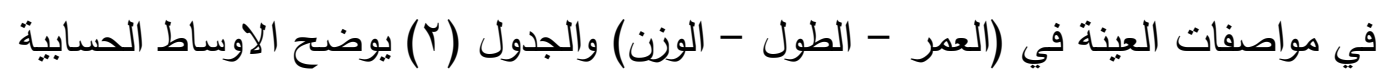
والانحرافات المعيارية للمتغيرات المعتدة في التكافؤ. 


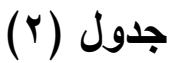

يوضح الاوساط الحسابية والانحرافات المعيارية للمتغيرات المعتمدة في التكافؤ

\begin{tabular}{|c|c|c|c|c|c|c|}
\hline \multirow{2}{*}{ الجدولية } & \multirow{2}{*}{ المحتسبة } & \multicolumn{2}{|c|}{ التجريبية الثانية } & \multicolumn{2}{|c|}{ التجريبية الاولى } & \multirow{2}{*}{ المواصفات } \\
\hline & & $\varepsilon^{r} \pm$ & بَ" & $\varepsilon^{\prime \pm}$ & اسَ & \\
\hline \multirow{4}{*}{$r, Y T$} & 1,00 & $\cdot, V \varepsilon$ & $M, 1 Y$ & $\cdot, 9$ & $11, \mathrm{~V}$ & العمر / السنة \\
\hline & $\cdot, \Lambda$. & 1,90 & $17 V, V$ & r, & $17 \wedge, \wedge$ & الطول / سم \\
\hline & $\cdot, 97$ & $r, 0 \varepsilon$ & $\pi T^{2}$. & $r, 1 \Lambda$ & $71, Y$ & الوزن / كغم \\
\hline & $1, v_{1}$ & $\cdot, r \cdot$ & 0,01 & $\cdot, r$. & $0, V_{0}$ & يارد / ثانية اختبار العدو •ع \\
\hline
\end{tabular}

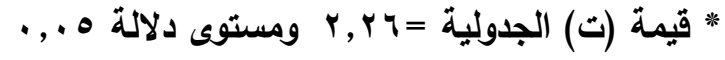

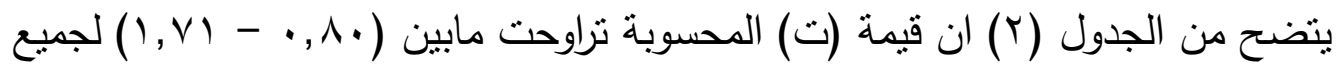
المتغيرات ، وعند مقارنتها بقيمة (ت) الجدوليـة عند درجة حريـة (1) وامـام مسنوى (0. , •) ظهر انها تساوي (Y, Y T) وهي اكبر من قيمـة (ت) المحسوبة ، وذلك يدل على عدم وجود فروق ذات دلالة معنوية بين مجموعتي البحث في المتغيرات المعتمدة في التكافؤ. و ومن ثم

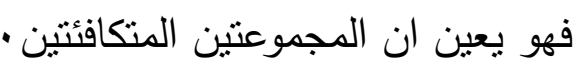

ب- ع ادوات البحث: - الاستبيان - الاجهزة و الادوات المستخدمة - الدصادر و المراجع العربية

ب-0 الاجهزة الادوات المستخدمة:

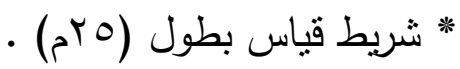
" ساعة الكترونية نوع (casio) عدد (ع).

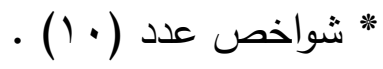
* اعلام عدد (0) (0) 


$$
\begin{aligned}
& \text { بـ ـ القياسات و الاختبار ات المستخدمة (طول - الوزن): } \\
& \text { r-1-1 قياس الطول : }
\end{aligned}
$$

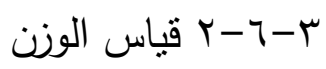

$$
\begin{aligned}
& \text { r-ז-r قياس اختبار عدو (•؛) ياردة (• (1) مرات }
\end{aligned}
$$

الهدف من الاختبار : قياس القدرة اللاهوائية - طريقة الاداء : احماء بسيط ثم الجري السريع لمسافة (• ع) يارد يكرر ذللك (• ( ) مرات باقصى مجهود ، على ان تكون فترات الرحة بين كل مرة واخرى (Yo) ثانية .

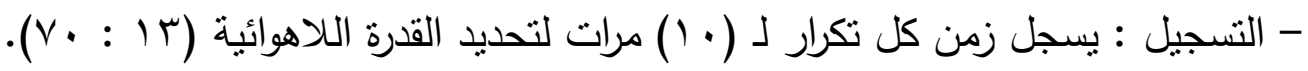

ب - - - ـ قياس معدل النبض:

لحساب معدل ضربات القلب في الدقيقة بعد الجهد تم القياس باستخدام جس النبض

للشريان السباتي (Artery Carotide) في منطقة اسفل الذقن بالاصابع وحساب عدد ضربات القلب في خلال (10) ثانية ثم ضرب الناتج × ع.

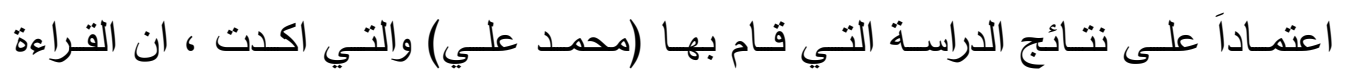

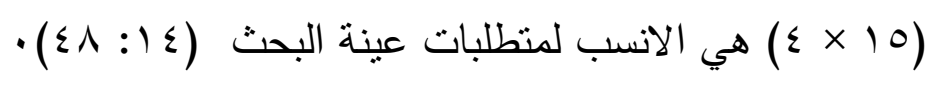

ب-7 - ـ قياس معدل التنفس:

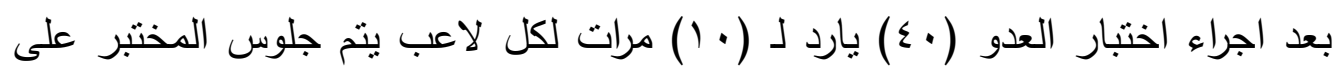
مقعد مباشرة لقياس عدد مرات التنفس في الدقيقة الواحدة ، ويعطي تعليمات نتثير بان الاختبار هو لقياس معدل النبض الذي يقوم باختبار يحسب عدد مرات التي يرتفع الصدر في اثناء

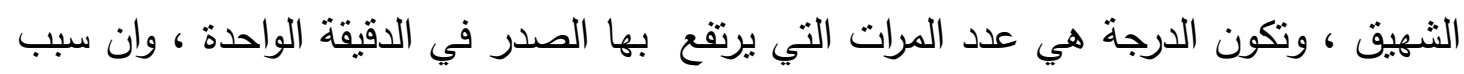

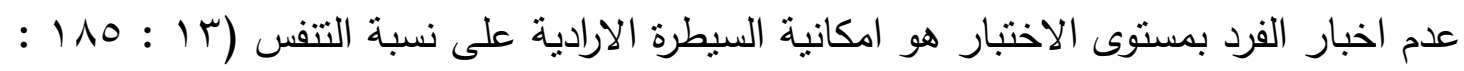
$\cdot(1) 4$ 
r V_ خطوات اجر اء البحث الميدانية :

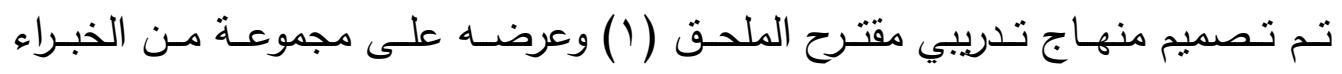
والمختصين (") اذ تضمن المنهاج التدريبي مجموعة من التمارين البدنية والمهارية تمارس من قبل مجموعتين تجريبيتين في منطقة العمل الثانية من مناطق التدريب الفتري الجزء الاول والثاني

باختلاف الزمن و كما هو مبين في الجدول (1) .

ب-V- ا التجربة الاستطلاعية: - قام الباحثان مع فريق العمل(") باجراء تجربة الاسنطلاعية على (ه) لاعبين من مجتمع

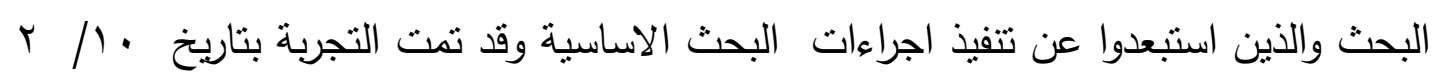

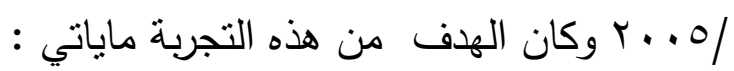
- التعرف على الاخطاء والمعوقات التي قد نرافق التجربة . - حساب الوقت لتتفيذ الاختبارات . - التأكد من صلاحية الاجهزة والادوات المستخدمة. - التأكد من كفاءة فريق العمل في تتفيذ القياسات والاختبارات.

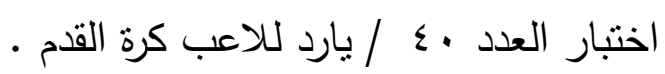
r-V-r اجري الاختبار القبلي على عينة البحث فبل البدء بتتفيذ المنهاج التدريبي وذللك لتحديد

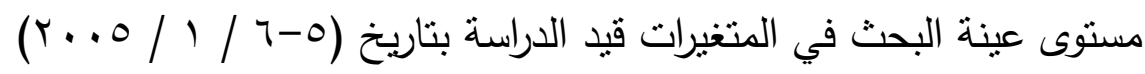
(") - أ.د. ياسين طه/كلية التربية الرياضية / جامعة الموصل.

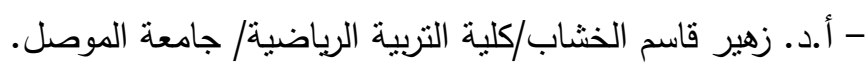

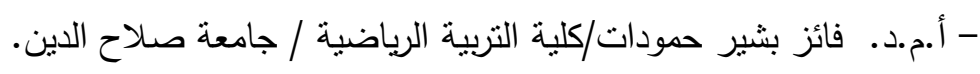

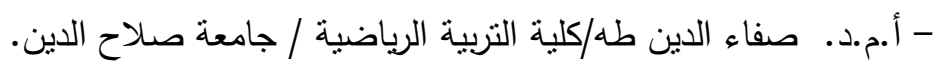

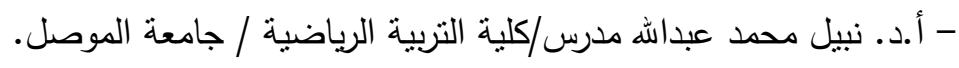

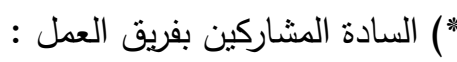

- م.م • سامان حمد سليمان/كلية التربية الرياضية / جامعة صلاح الدين.

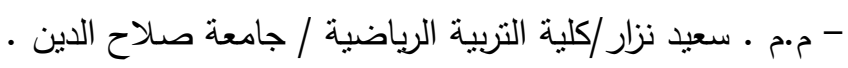
- م.م • فريدون حسن/كلية التربية الرياضية / جامعة صلاح الدين. 


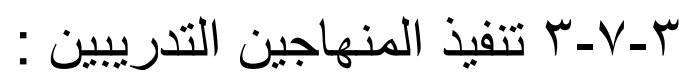

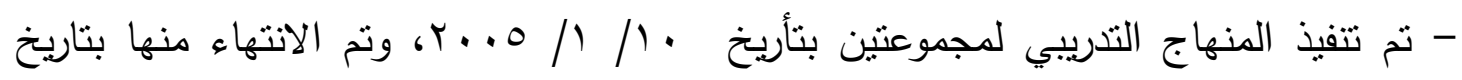

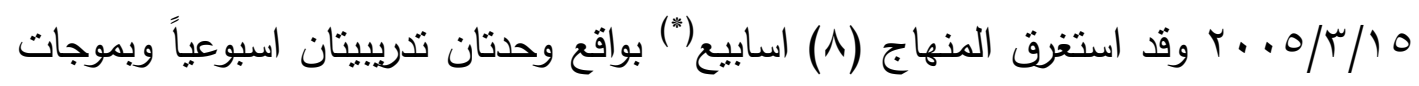

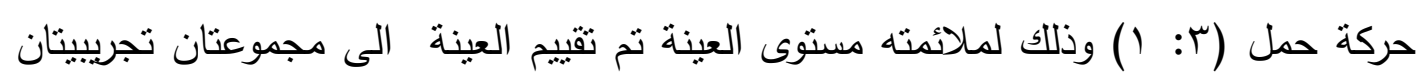

$$
\text { وكما يلي: }
$$

- المجموعة التجريبية الاولى : تستخدم التثريب الفتري الذي تقع (ازمنته) في المنطقة الثانية

$$
\text { الجزء الاول من جدول (1) - (1) }
$$

- المجموعة النجريبية الثانية : تستخدم التنريب الفتري الذي تقع (ازمنته) في المنطقة الثنانية

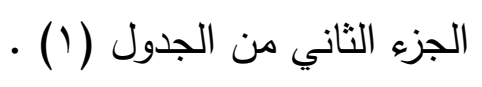

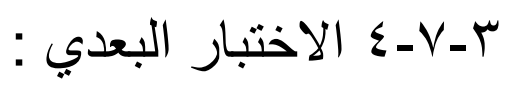

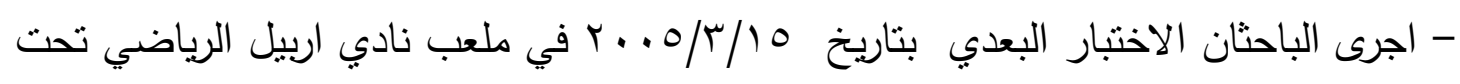
نس الظروف الزمانية والمكانية للأختبار القبلي وعلى نفس الاختبارات.

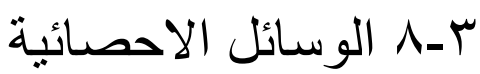

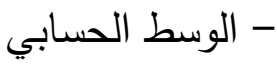

$$
\begin{aligned}
& \text { - الانحراف المعياري. - التابي. } \\
& \text { - اختبار (t) للعينات غير المرتبطة }
\end{aligned}
$$

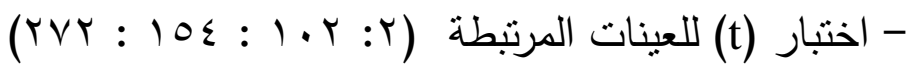

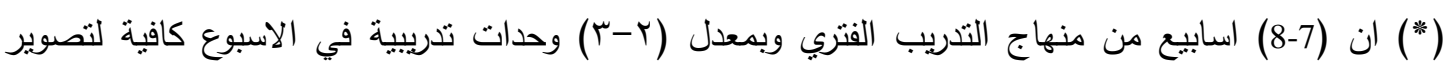

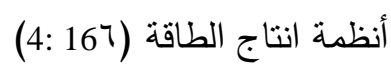


ع - عرض النتائج وتحليلها ومناقثتها . ـ ـ ا عرض عرض التحليل ومناقثة نتائج الاختبارين القبلي و البعدي لمتغيرات

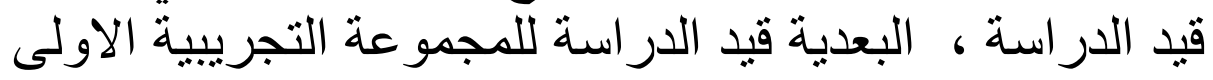

جدول (آ)

المعاليم الاحصائية للاختبارين القبلي والبعدي للمتغيرات للمجموعة التجريبية الاولى التئ

\begin{tabular}{|c|c|c|c|c|c|c|}
\hline \multirow{2}{*}{ المحسوية } & \multicolumn{2}{|c|}{ الاختبار البعدي } & \multicolumn{2}{|c|}{ الاختبار القبلي } & \multirow{2}{*}{\multicolumn{2}{|c|}{ 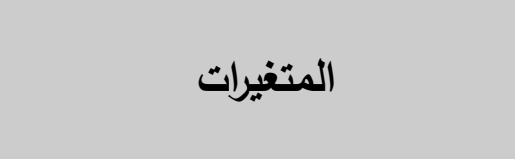 }} \\
\hline & $\varepsilon^{+}$ & سَ & $\varepsilon_{+}^{+}$ & سن & & \\
\hline$* 0,17$ & $\cdot, r$. & $\varepsilon, \wedge 9$ & $\cdot r$ & $0, v_{0}$ & $(1 \cdot)$ & مرات / ثتبـار العـدو (•ـ) يـار \\
\hline "*Y, TY & $\varepsilon, \varepsilon \wedge$ & Or, 9 & $\varepsilon, \vee \wedge$ & Tr, & | عدد & قرات في الدقيقة/ بعد الجه \\
\hline$* r, \cdot r$ & $\varepsilon, Y v$ & $17 \cdot, \mathrm{V}$ & $7, \leqslant 7$ & $17 \lambda, \Lambda$ & ادق & قياس معدل سرعة النبض \\
\hline$\left.{ }^{*} Y, T\right)$ & $0, \Lambda r$ & $1 T r, \lambda$ & 7,71 & $1 \leqslant 0,0$ & | بدق & / دق بعد الجهد / في فتزرة \\
\hline${ }^{*} Y, Y \mu$ & $7, \Lambda)$ & $T<\varepsilon, 0$ & $0, .$. & $|m|, 0$ & كادق & الاستثتفاء \\
\hline
\end{tabular}

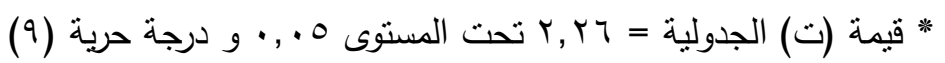

يبين الجدول (ץ) الاوساط الحسابية والانحرافات المعيارية للاختبار القبلي لدتغير القدرة

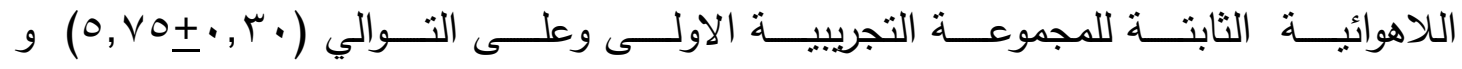

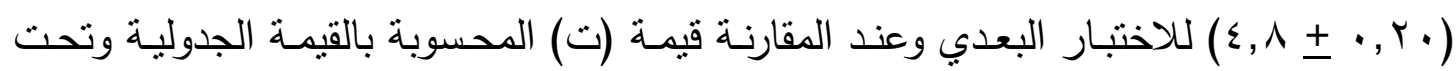

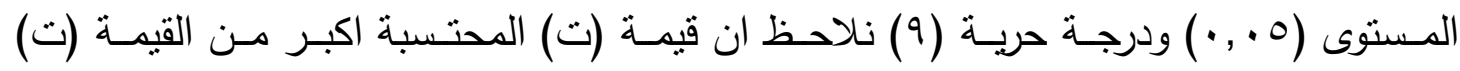

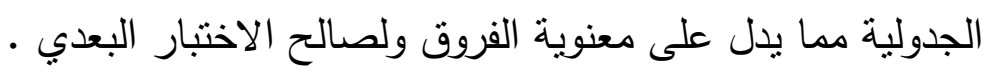

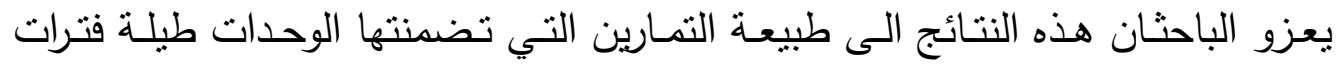

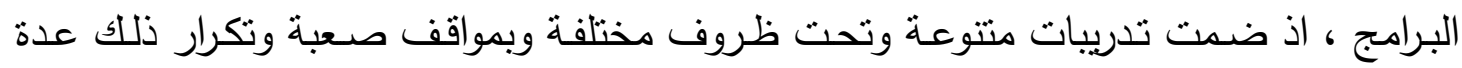

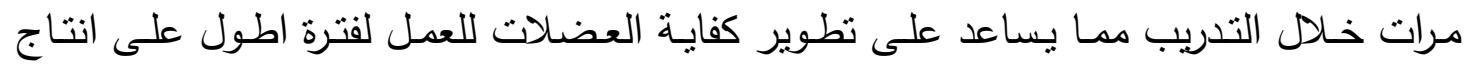

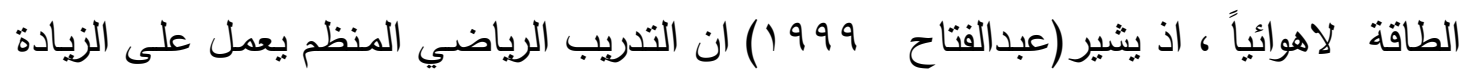

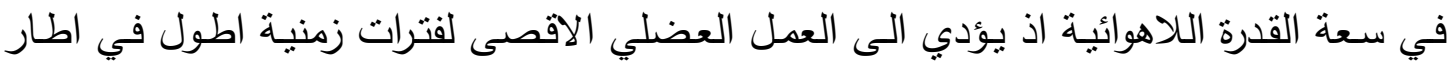

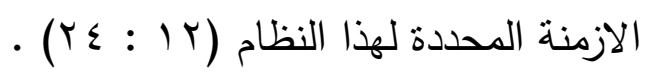
ومن جدول (r) نفسه نلاحظ ايضاً ان الوسط الحسابي والانحراف العبياري لعدد مرات

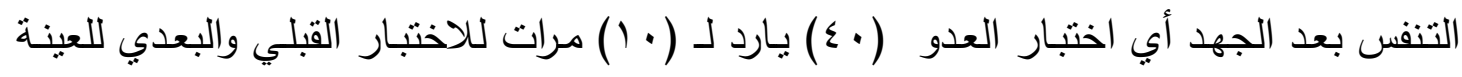

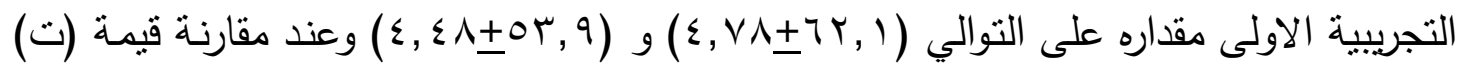


بالقيمـة الجدوليـة ـ تحت مستوى خطـأ (0. . ·) وعند درجـة حريـة (9) نلاحظ ان قيمـة (ت) المحنسبة اكبر من القيمة الجدولية مما يدل على معنوية الفروق ولصالح الاختبار البعدي. ويرى لئه

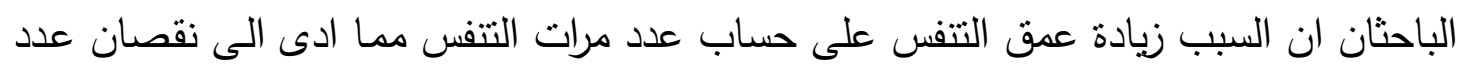

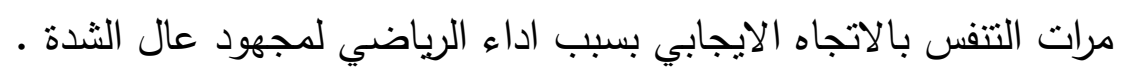

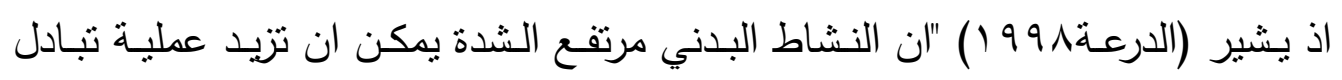

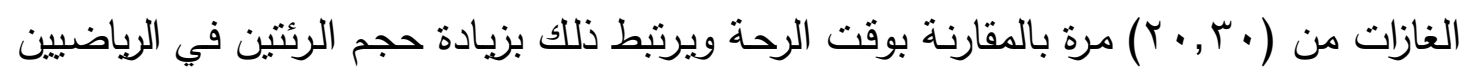

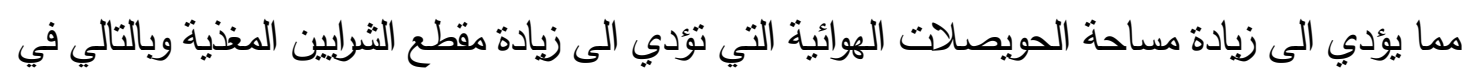

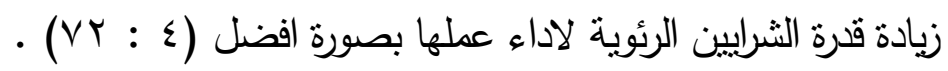
ومن الجدول (r) كذلك نلاحظ ان القيم المحسوبة لمتغير النبض للاقائق (الاولى -الثانية

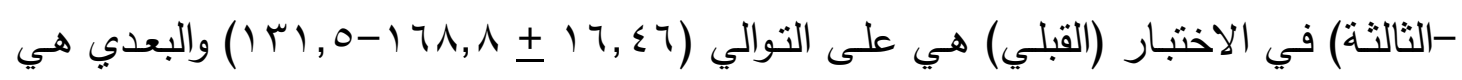

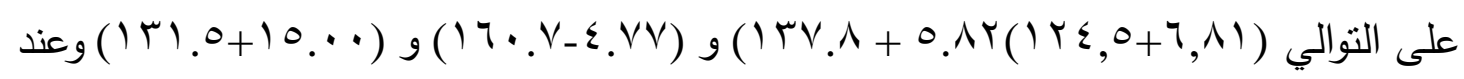

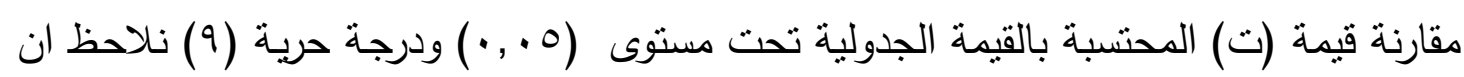
قيمة (ت) المحتسبة اكبر من قيمة (ت) الجدولية مما يدل على معنوية الفروق ولصالح الاختبار

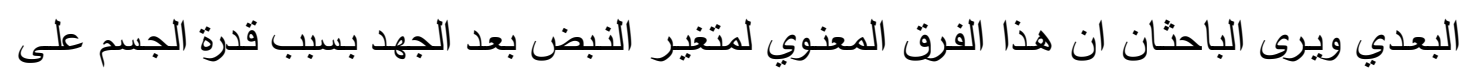

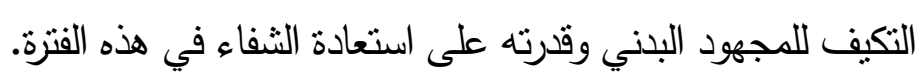

ع - عرض و تحليل ومناقشة نتائج الاختبارين القبلي والبعدي للمتغيرات قيد الدر اسة للمجمو عة التجريبية الثانية.

جدول (๕)

المعاليم الاحصائية والقبلية والبعدية للمجموعة التجريبية الثانية ولمتغيرات قيد الدراسة

\begin{tabular}{|c|c|c|c|c|c|c|}
\hline \multirow{2}{*}{ المسوية } & \multicolumn{2}{|c|}{ الاختبار البعدي } & \multicolumn{2}{|c|}{ الاختبار القبلي } & \multirow{2}{*}{\multicolumn{2}{|c|}{ المتغيرات }} \\
\hline & $\varepsilon \pm$ & سَ & $\varepsilon \pm$ & سَ & & \\
\hline$* q, r$ & $\cdot, 11$ & $\varepsilon, \wedge r$ & $\cdot, \cdot r$ & 0,01 & \multicolumn{2}{|c|}{ مرات / اختـار العـدو (•؛) يـارد (· (1) } \\
\hline$* Y, \leqslant 0$ & $T, Y V$ & $0 \cdot, 1$ & $0, \leqslant r$ & $71, \varepsilon$ & \multicolumn{2}{|c|}{ مرات في الدقيقة/ بعد الجهر مـات التنفس / عدد } \\
\hline$* \varepsilon, 1 r$ & $r, q)$ & 107,1 & $r, \uparrow$. & Iד,V & | ادق & قياس معدل سرعة النبض \\
\hline$* \varepsilon, \cdot 7$ & $\varepsilon, \cdot \wedge$ & $10 \cdot, 0$ & r & $10 \mathrm{~V}, 0$ & ب إق & / دق بعد الجهد / في فترة \\
\hline$* Y, \vee \wedge$ & $\varepsilon, O Y$ & $1 r v, q$ & $\varepsilon, \varepsilon \wedge$ & $1 \leqslant r, \Lambda$ & | - ل ادق & الاستشفاء \\
\hline
\end{tabular}

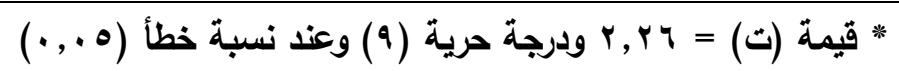


يبين الجدول (ع) الاوساط الحسابية والانحرافات المعيارية للاختبار القبلي لمتغر القدرة

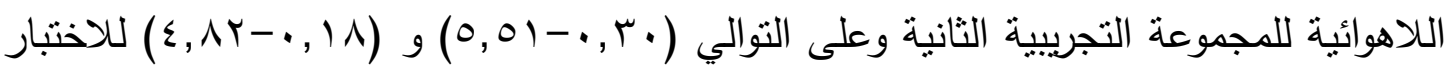

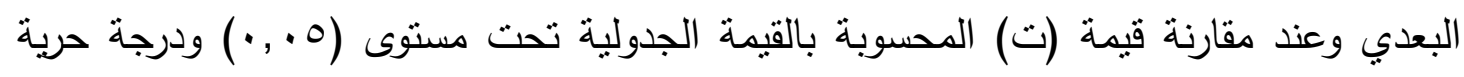
(9) نلاحظ ان قيمة (ت) المحسوبة اكبر من قيمة (ت) الجدولية مما يدل على معنوية الفروق

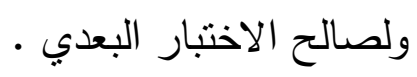

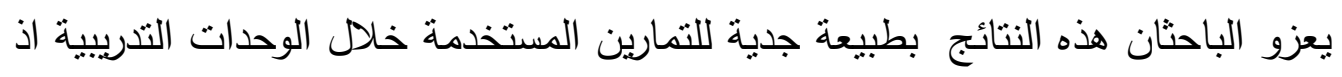

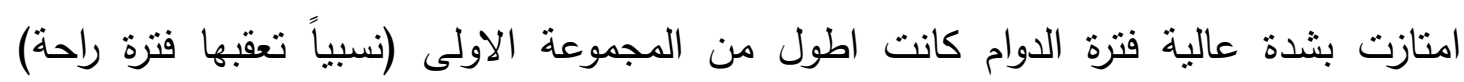

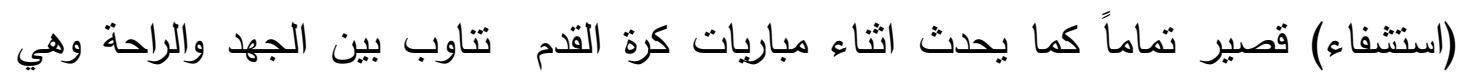

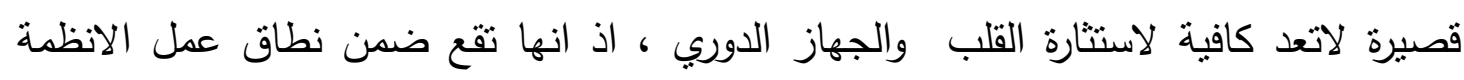

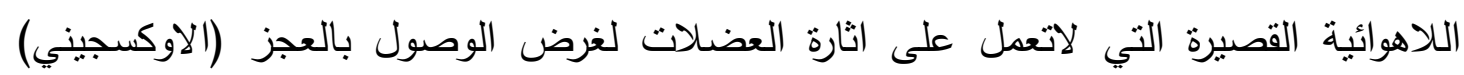

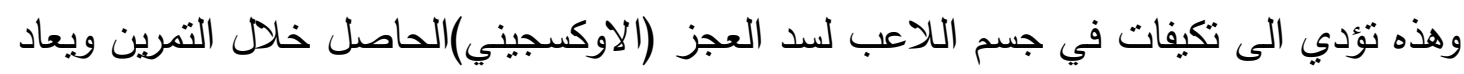

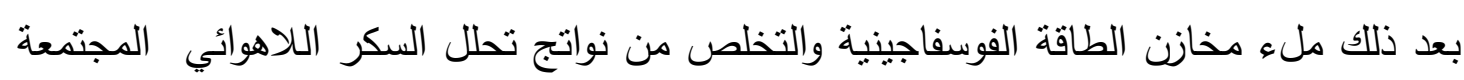

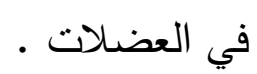

ومن الجدول (ع) نلاحظ ايضاً الوسط الحسابي والانحراف المعياري لمتغير عدد مرات

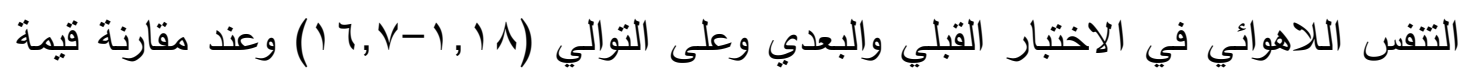

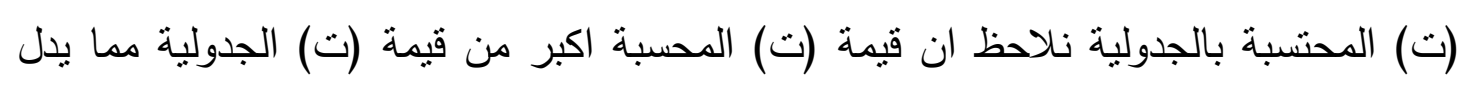

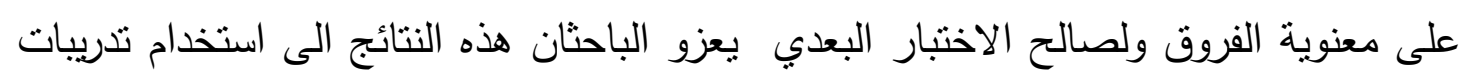

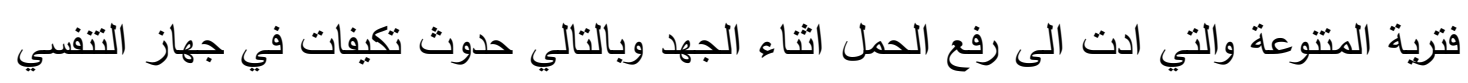

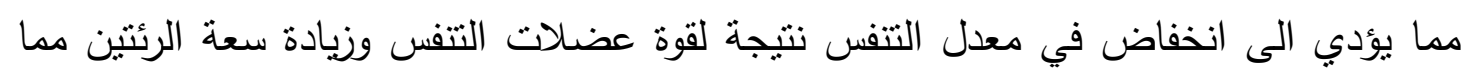
يؤدي الى زيادة في عمق التنفس . ومن جدول (ع) ايضاً نلاحظ ان القيم المحسوبة لمتغير النبض للادقائق الثلاث في

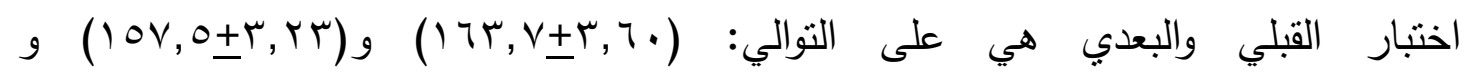

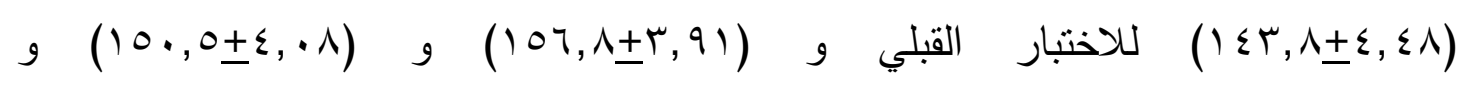

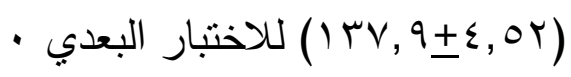


ع -r عرض و تحليل ومناقثة نتائج الاختبار ات البعدية للمجمو عتين الاولى و الثانية وللمتغير وات قيد الدر اسة :

جدول (0)

المعاليم الاحصائية للاختبارات البعدية للمجموعتين ولمتغيرات قيد الدارسة

\begin{tabular}{|c|c|c|c|c|c|c|}
\hline \multirow{2}{*}{ المحسوية } & \multicolumn{2}{|c|}{ التجريبية الثانية } & \multicolumn{2}{|c|}{ التجريبية الأولى } & \multirow{2}{*}{\multicolumn{2}{|c|}{ المتغيرات }} \\
\hline & $\varepsilon \pm$ & س س & $\varepsilon^{+}$ & س - س & & \\
\hline$\cdot, \wedge \vee$ & $\cdot, 11$ & $\varepsilon, \wedge Y$ & $\cdot, r \cdot$ & $\varepsilon, \wedge 9$ & $(1 \cdot)$ & مرات / اختبـار العـدو (•؛) يــارد \\
\hline $1, \varepsilon$. & $\checkmark, Y V$ & $0 ., 1$ & $\varepsilon, \varepsilon \wedge$ & or,,$q$ & عدد & مرات في الدقيقة/ بعد الجهد التنفس \\
\hline$r, .0$ & $r, 91$ & 107,1 & $\varepsilon, V Y$ & $17 \cdot, V$ & 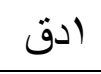 & قياس معدل سرعة النبض | \\
\hline דצ, & $0, \Lambda Y$ & $1 r v, \Lambda$ & $\varepsilon, \cdot \uparrow$ & $10 \cdot, 0$ & كدق & / دق بعد الجهد / في فترة | \\
\hline$* Y, V Y$ & $7, \wedge 1$ & $\mid r \leqslant, 0$ & $\varepsilon, O Y$ & $1 r v, 9$ & سدق & الاستشفاء \\
\hline
\end{tabular}

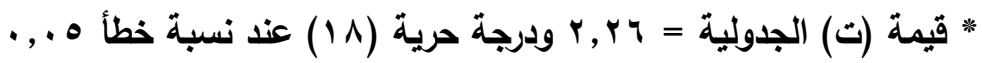

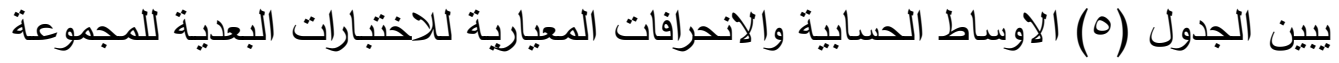

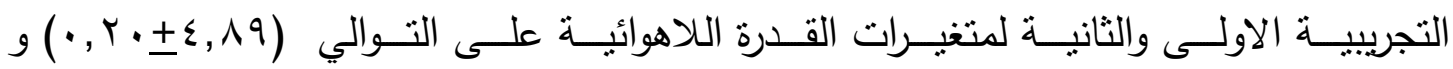

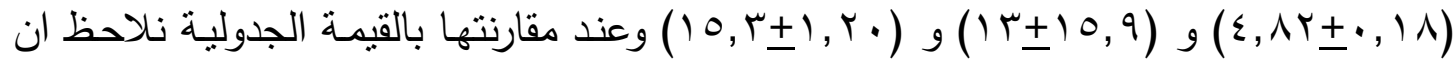

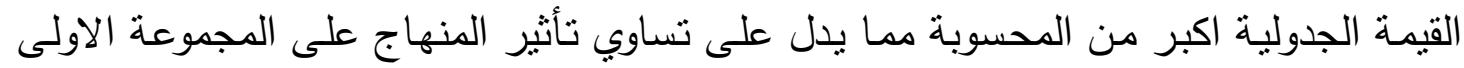

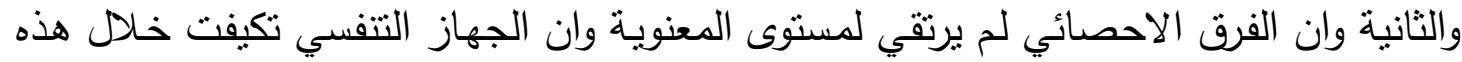

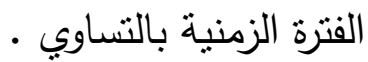

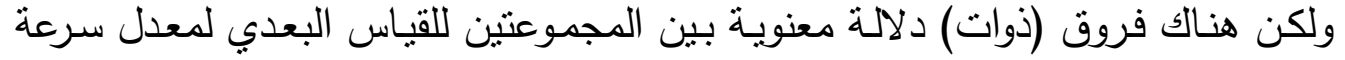

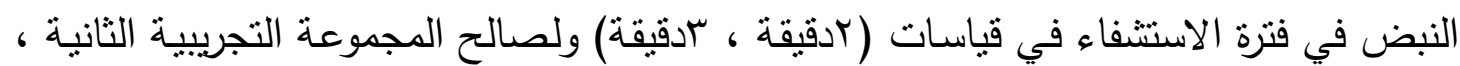

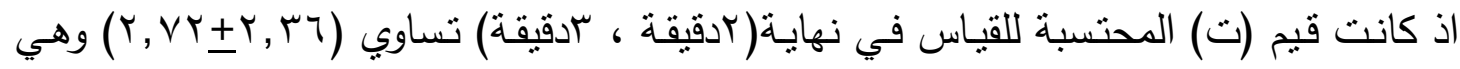

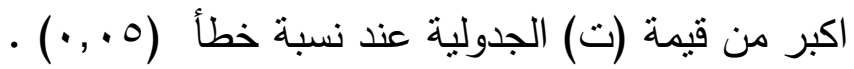

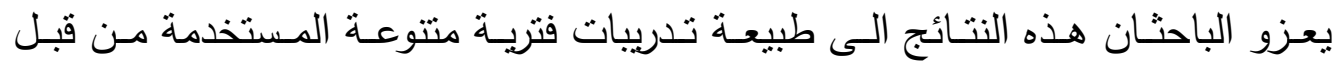

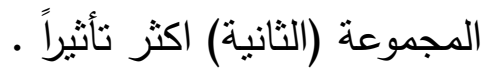
ان نتائج البحث الحالي لها اهمية كبيرة بالنسبة للاعبي كرة القدم الثباب و التي يمكن

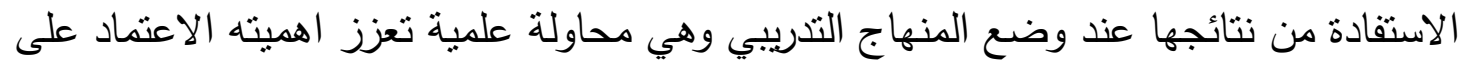

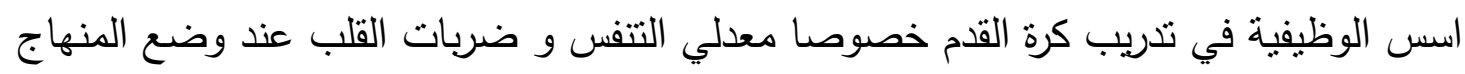
التنريبي ، لان هذه العينة نحتاج الى ابتالائها اهتماما استثنائيا في مجال كرة القدم ولها تاثير 
مباشر على بناء قاعدة صحيحة للعبة و الحصول على افضل نتائج مستقلية باعتبارهم ثلث

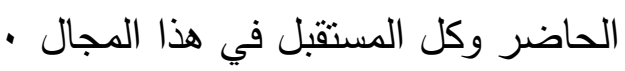

ومن جانب اخر فان الناحية الوظيفية للاجهزة الدورية و التنفسية تكتمل وتؤدي وظائفها

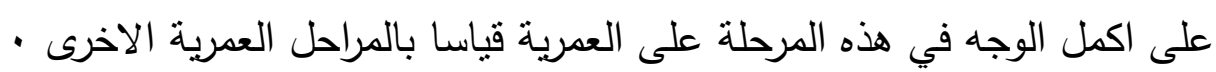

0 - الاستنتاجات و التوصبات

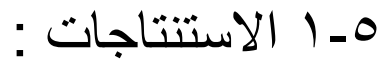

1. احدث برنامجي التدريب الفنري انخفاضاً في معدل النبض ومعدل التتفس في فترة الاستشفاء

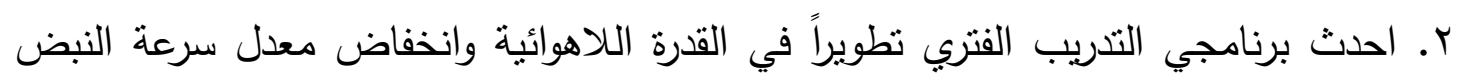
وعدد مرات التتفس لاى عينة البحث الثانية بشكل أكبر .

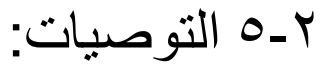

ا ـ ضرورة استخدام تدريبات فترية متتوعة في تدريب كرة القدم للتأثثر الايجابي لهذه التدريبات

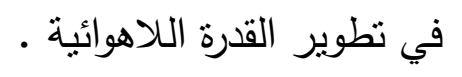

r. التأكيد على مدربي كرة القدم الاعتماد على القياسات الوظيفية ومنها معدل ضربات القلب والتتفس عند وضع البرامج التنريبية ليتسنى لهم وضع الحمل التدريبي المناسب للوحدات

$$
\text { التدريبية . }
$$

r. التاكيد على مدربي كرة القدم بتتظيم الحمل التدريبي عند وضع برامج التدريبية على وفق التق

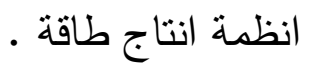




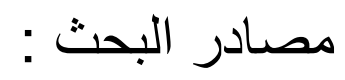

ا ـ مجدي عزيز ابراهيم (901 (1)): قراءات في المناهج طب، مكتبة النهضة المصرية r. وديع ياسين التكربيتي و حسن العبيدي (ا79 1) : التطبيقات الاحصائية في بحوث التربية الرياضبة.

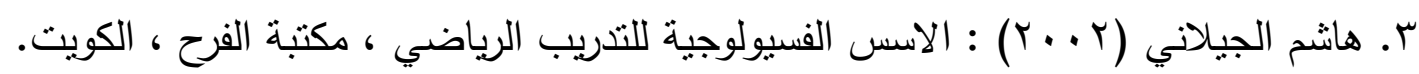
ع. شاكر فرهود الدرعة (1911) ) : علم التدريب الرياضي ، ط (منشورات ذات سلاسل الكويت. ه. ريسان مجيد خربيط (9VI (IVI) : تطبيقات في علم فسيولوجيا والتدريب الرياضي ، عمان دار الثروق.

7. رشدي فتوح عبدالفتاح (r/91 ) اساسيات عامة في علم الفسيولوجيا ، طب ، ذات سلاسل

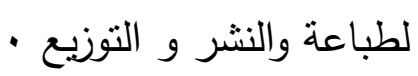
V. قيس ابراهيم الدوري و طارق عبدالملك الامين (ب ت): الفسلجة لطلاب كلية التلربية الرياضية البران ^. نزار الطالب ، و محمد السامرائي (1911) : مبادىء الاحصاء والاختبارات البدنية والرياضية ، دار الكتب للطباعة والنشر ، جامعة موصل. 9 . عزت عبدالرحمن ، و محمود كامل (1911) : جسم الانسان ، ط امؤسسة دار العلوم ، الكوبت. • 1. محمد حسن علاوي ، و ابو العلا عبدالفتاح (ع 9 1 ) : فسيولوجيا التذريب الرياضي ، دار

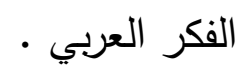

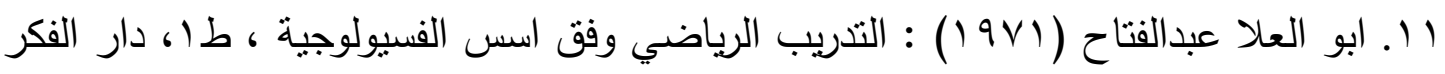

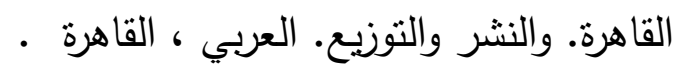

r ا. ابو العلا عبدالفتاح (999 (19) : التدريب الرياضي وفق اسس الفسيولوجية، طا ، القاهرة با. محمد علي القط (999 (199) : وظائف اعضاء التدريب الرياضي ، طا (، دار الفكر ، القاهرة

ع ا. محمد علي ، ياسين طه (19719) : الاختلاف في قراءة النبض بعد الجهد اللاهوائي ، المشترك الهوائي،بحث منشور في مجلة الرافدين للعلوم الرياضية المجلد (ب) العدد (ع) . 1 . ياسين طه الحجار (ع 99 1) : الاستجابات الوظيفية العضلية بعد العدو المسافات الطويلة في الجو الحار والمعتلا ، اطروحة دكتوراه جامعة الموصل ، كلية التربية الرياضية.

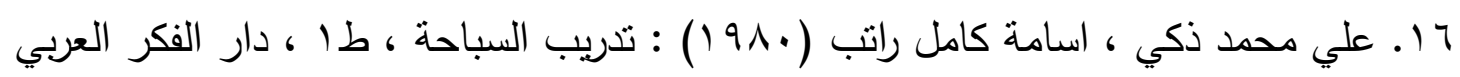

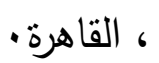


V ا. محمد نصر الدين رضوان (911) (191) : طرق قياس الخهر البدني في الرياضة ، طا ،

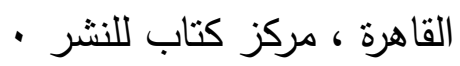

18. Bucher, T, total training, malon puplisher, Sweden , 1982.

19. Fox , E.L at mathews , D.K. (1974): interval training conditioning sport and general fitness, W.B. Saunders Campany philadelphia.

20. Guyton , A.C. (1986): Text book of medical physiology : W.B.C. under U.S.A.

21. Macardel , W.O , etal (1989): Exercise physiology, energy Nutratin and Human performance lea fibiger.

22. karpiovichp. And sining w.(1971) : physiology of musculer activity, $7^{\text {th }}$ ed., philadelphia w.b. saunder co.

23. Astrand p.o.and Randahle, k (1977): Text book of work physiology, MCGraw-Hill Book company, U.S.A

24. Dare, B.(1979) : Running and body, Applying physiology to track training, Tafa News press. 


\section{الملحق (r)}

التمارين البدنية والمهارية المستخدمة في البرنامج التدريبي لدى المجموعتين التجريبيتين لتطوير القدرة اللاهوائيه

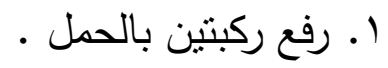

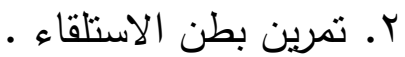

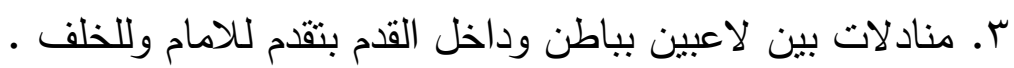
ع. ضرب الكرة بالرأس (كرة معلقة) . ل

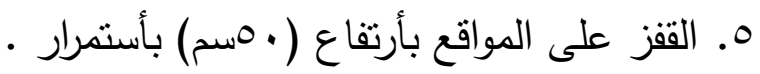
7.

V. منادلات بكافة اجزاء القدم • يتبادل المراكز بين لاعبين بشكل مستمر • رصائ

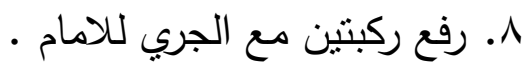

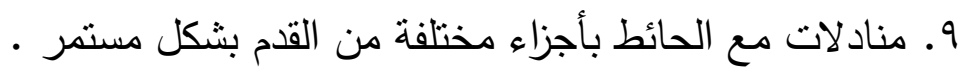

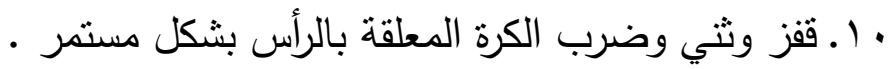

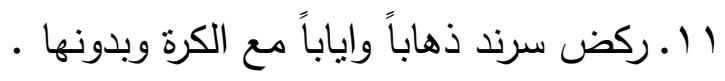

r ا ـ الدحرجة بين الثواخص ثم منادله الى الجداره استلام الكرة ثم اعادة نفس العملية باستمرار .

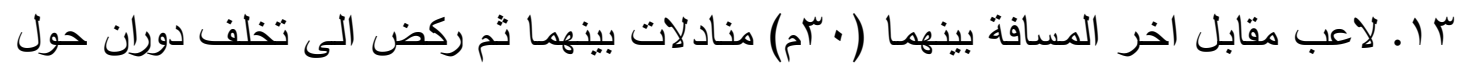

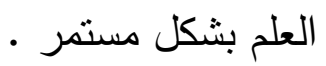

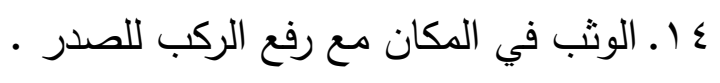

10 ـ رمي الكرة الى لاعبي ، الجلوس على الارض ، اضعماد الكرة باستمرار .

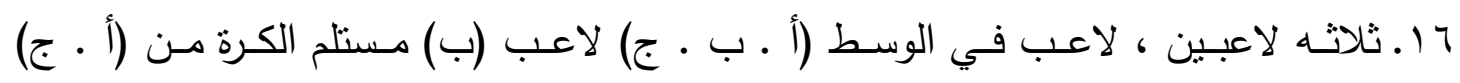

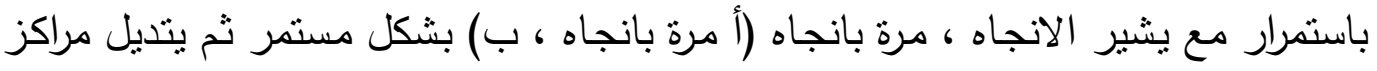
بينهما

V V ا الجرى بالكرة من جدار الى جدار المسافة بين جدارين (• بام) قبل الوصول الى الجدار تمرير الكرة للحائط ثم استفبالها و لسيطرة عليها ثم قيادة الكرة للحائط الثاني باستمرار .

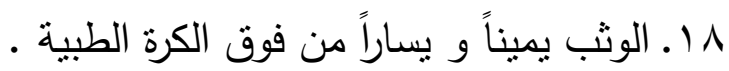

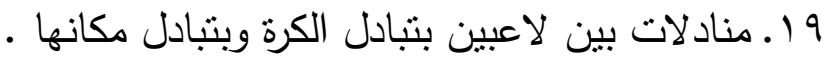

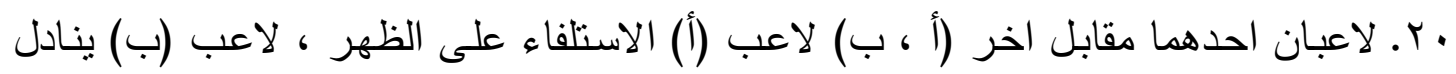

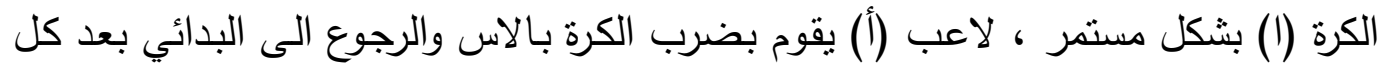

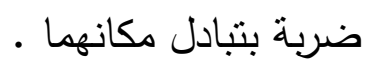




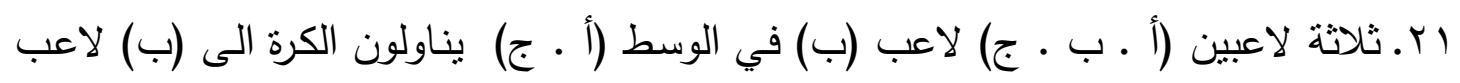

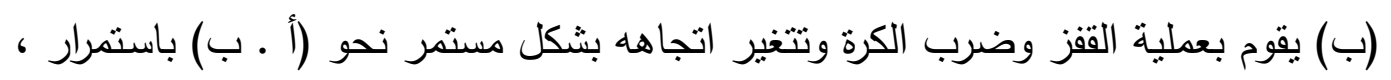

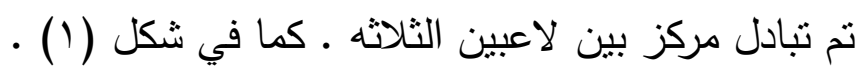

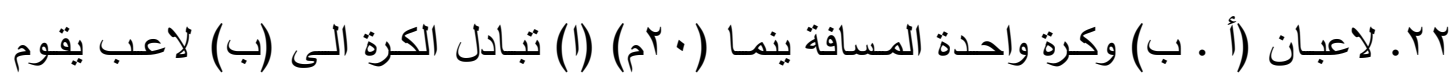

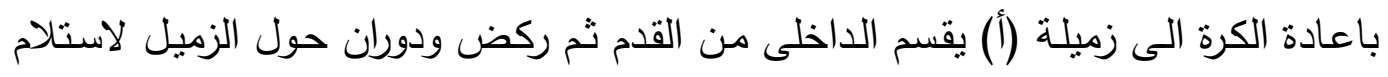

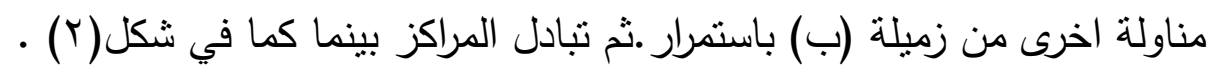

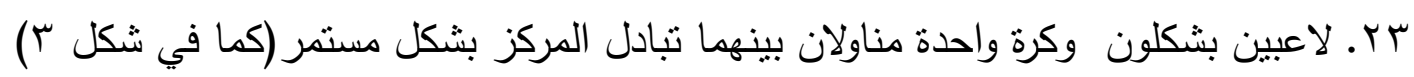

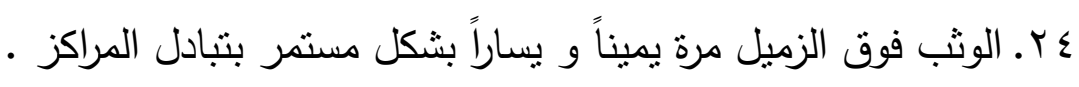




\begin{tabular}{|c|c|c|c|c|c|c|c|}
\hline \multirow{2}{*}{\multicolumn{2}{|c|}{ راحة بين }} & \multirow{2}{*}{ المجاميع } & \multirow{2}{*}{ التكرارات } & \multirow[b]{2}{*}{ زمن دوام المثير } & \multirow[b]{2}{*}{ الزمن / دقيقة } & \multirow[b]{2}{*}{ التمارين } & \multirow[b]{2}{*}{ المجموعة التجريبية الاولى } \\
\hline & & & & & & & \\
\hline 180 + 120 ثانية & $8 \times 90$ & 2 & 5 & 30 ثانية & 22.0 & (1) : ت & \multirow{4}{*}{ الوحدة التدرييية / الاولى } \\
\hline \multirow[t]{3}{*}{ 240 + 300} & $8 \times 90$ & 2 & 5 & 30 & 26.0 & (2) : ت & \\
\hline & $4 \times 90$ & 2 & 5 & 30 ثانية & 8.5 & (3) : ت & \\
\hline & & 5 & 20 & $\mathrm{~L} / 150$ & المجموع 0. 56 & & \\
\hline 180 + 120 ثانية & $8 \times 120$ & 2 & 5 & 40/ ثانية & 27.66 & (1) : ت & \multirow{4}{*}{ الاولىموعة التجرييية / الثانية الوحدة } \\
\hline \multirow[t]{2}{*}{ 240 ثانية } & $4 \times 120$ & 1 & 5 & 40/ ثانية & 15.00 & (3) : ت & \\
\hline & $4 \times 120$ & 1 & 5 & 40 ثانية & 11.33 & (4) : ت & \\
\hline 120 ثانية & $4 \times 90$ & 4 & 25 & 200/ ثانية & 54.32 & & \\
\hline 180 + 180 & $8 \times 90$ & 1 & 5 & 30 & 10.5 & (2): & \multirow{4}{*}{ الاولى المموعة التجريبية الاولى / الوحدة } \\
\hline \multirow[t]{4}{*}{ 300 ثانية } & $8 \times 90$ & 2 & 5 & 30 ثانية & 25.66 & (7) : ت & \\
\hline & & 2 & 5 & 30 & 23.66 & (6) : ت & \\
\hline & & 5 & 25 & 150 ثانية & المجموع59.82 & & \\
\hline & $4 \mathrm{X} 120$ & 1 & 5 & ا ثانية & 13.33 & ت: (2) & \multirow{4}{*}{ الاولىموعة التجريبية الاولى / الوحدة } \\
\hline 120 ثانية & $8 X 120$ & 2 & 5 & 40 ثانية & 29.66 & (7) : ت & \\
\hline \multirow[t]{2}{*}{ 240 + 180 ثانية } & $4 \mathrm{X} 120$ & 1 & 5 & ا 40 ثانية & 11.33 & (6) & \\
\hline & & 4 & 20 & & المجموع 54.32 & & \\
\hline
\end{tabular}

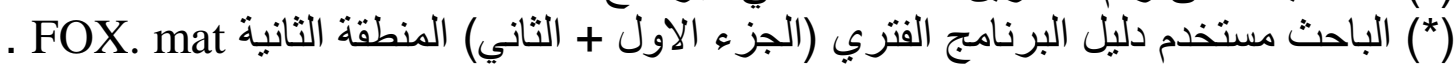

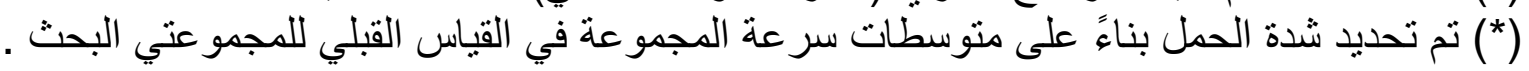




\section{مفردات البرنامج التدريبي \\ الاسببوع : الثاني}

الوحدة : الوحدة الاولى + الوحدة الثانية

\begin{tabular}{|c|c|c|c|c|c|c|c|}
\hline \multicolumn{2}{|c|}{ راحة بين } & \multirow{2}{*}{ المجاميع } & \multirow{2}{*}{ التكرارات } & \multirow{2}{*}{ زمن دوام المثير } & \multirow{2}{*}{ الزمن / دقيقة } & \multirow{2}{*}{ التمارين } & \multirow{2}{*}{ المجموعة التجريبية الاولى } \\
\hline مجموعة & تكرار & & & & & & \\
\hline 120/ ثانية & $4 \times 90$ & 1 & 5 & 30 ثانبة & 10.5 & $(5): ت$ & \multirow{4}{*}{ الوحدة التدرييية / الاولى } \\
\hline 180- 240 /ثانية & $8 \times 90$ & 2 & 5 & 30 ثانية & 24.0 & (9): ت & \\
\hline \multirow[t]{2}{*}{300 /ثانية } & $8 \times 90$ & 2 & 5 & 30 ثانية & 22.0 & $(8): ت$ & \\
\hline & & 5 & 25 & د/150 & المجموع 56 . & & \\
\hline 120 ثانية & $4 \times 120$ & 1 & 5 & 40/ ثانية & 13.33 & $(5): ت$ & \multirow{4}{*}{ 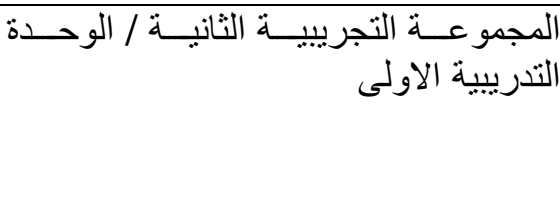 } \\
\hline 240 + 180/ ثانية & $8 \times 120$ & 2 & 5 & 40 ثانية & 29.66 & $(8): ت$ & \\
\hline \multirow[t]{2}{*}{300} & $4 \times 120$ & 1 & 5 & 40 ثانية & 16.33 & (9): & \\
\hline & & 4 & 20 & & المجموع 32 ـ 59 & & \\
\hline 180 + 120ثانية & $8 \times 90$ & 2 & 5 & 30 ثانية & 22.0 & ت: & \multirow{4}{*}{ التدريبية الثانية التجريبيــة الاولــى / الوحـــة } \\
\hline 240ثانية & $4 \times 90$ & 1 & 5 & 30 ثانية & 12.5 & (8) : ت & \\
\hline \multirow[t]{2}{*}{ 300/ ثانية } & $8 \times 90$ & 2 & 5 & 30 ثانية & 22.0 & $(9): ت$ & \\
\hline & & 5 & 25 & 150 ثانية & المجموع56.5 & & \\
\hline 180 + 120نثانية & $8 X 120$ & 2 & 5 & 40/ ثانية & 27.66 & ت: (10) & \multirow{4}{*}{ 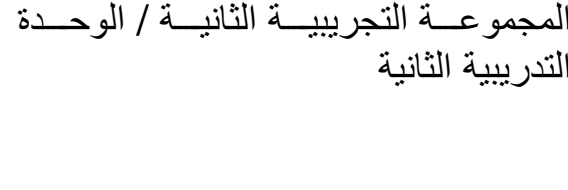 } \\
\hline 240 & $4 X 120$ & 1 & 5 & ا 40/ ثانية & 15.33 & (12) : & \\
\hline \multirow[t]{2}{*}{ 300/ ثانية } & $4 X 120$ & 1 & 5 & 40 40 ثانية & 16.33 & (13) & \\
\hline & & 4 & 20 & & المجموع 59.32 & & \\
\hline
\end{tabular}




\section{مفردات البرنامج التدريبي الاسبوع : الثالث و الرابع}

الوحدة : الوحدة الاولى + الوحدة الثانية

\begin{tabular}{|c|c|c|c|c|c|c|c|}
\hline \multicolumn{2}{|c|}{ راحة بين } & \multirow{2}{*}{ المجاميع } & \multirow{2}{*}{ التكر ارات } & \multirow{2}{*}{ زمن دوام المثير } & \multirow{2}{*}{ الزمن / دقيقة } & \multirow{2}{*}{ التمارين } & \multirow{2}{*}{ المجموعة التجريبية الاولى } \\
\hline مجموعة & تكرار & & & & & & \\
\hline 180 + 120 ثانية & $8 \times 90$ & 2 & 5 & 30 ثانية & 22.0 & (11): ت & \multirow[t]{4}{*}{ لوحدة التدريبية / الاولى } \\
\hline 240ثانية & $4 \times 90$ & 1 & 5 & 30 ثانية & 12.5 & (14): & \\
\hline \multirow[t]{2}{*}{ 300/ ثانية } & $8 \times 90$ & 2 & 5 & 30 ثانية & 22.0 & (16) : & \\
\hline & & 5 & 25 & /150 & المجموع 5 . 56 & & \\
\hline 180 + 120 ثنانية & $8 \times 120$ & 2 & 5 & 40/ ثنانية & 21.83 & (14) : & \multirow{4}{*}{ لمجريبية الاولى التجريبية الثانية / الوحدة } \\
\hline 240/ ثانية & $4 \times 120$ & 1 & 5 & 40/40 ثانية & 15.33 & (19) : & \\
\hline \multirow[t]{2}{*}{ 300 300 ثانية } & $4 \times 120$ & 1 & 5 & 40/ ثانية & 16.33 & (11): & \\
\hline & & 4 & 20 & 200/ ثانية & المجموع53.49 & & \\
\hline 120ثانية & $4 \times 90$ & 1 & 5 & 30 ثانية & 15.5 & (15): ت & \multirow{4}{*}{ لمجموعة التجريبية الثانية التيبة الاولى / الوحدة } \\
\hline 240+180 /ثانية & $8 \times 90$ & 2 & 5 & 30 ثانية & 24.0 & $(17): ت$ & \\
\hline \multirow[t]{2}{*}{ 300/300 ثانية } & $8 \times 90$ & 2 & 5 & 30 ثانية & 17.66 & ت & \\
\hline & & 5 & 25 & 150 ثانية & المجموع 57.16 & & \\
\hline 120ثانية & $4 \times 120$ & 1 & 5 & أثانية & 13.66 & ت: (17) & \multirow{3}{*}{ لمجموعة التجريبية الاولى التيانية / الوحدة } \\
\hline \multirow[t]{2}{*}{ 300/300 ثانية } & $4 \times 120$ & 1 & 5 & 40 ثانية & 16.33 & (18) : & \\
\hline & & 4 & 20 & 200/ ثانية & المجموع 59.63 & & \\
\hline
\end{tabular}


مفردات البرنامـج التدريبي

الاسبوع : الخامس و السادس

الوحدة : الوحدة الاولى + الوحدة الثانية

\begin{tabular}{|c|c|c|c|c|c|c|c|}
\hline \multicolumn{2}{|c|}{ راحة بين } & \multirow{2}{*}{ المجاميع } & \multirow{2}{*}{ التكرارات } & \multirow{2}{*}{ زمن دوام المثير } & \multirow{2}{*}{ الزمن / دقيقة } & \multirow{2}{*}{ التمارين } & \multirow{2}{*}{ المجموعة التجريبية الاولى } \\
\hline مجموعة & تكرار & & & & & & \\
\hline 120 ثانية & $4 \times 90$ & 1 & 5 & 30 ثانية & 10.5 & $(5): ت$ & \multirow[t]{4}{*}{ الوحدة التدريبية / الاولى } \\
\hline 240 + 180 & $8 \times 90$ & 2 & 5 & 30 ثانية & 24.0 & (9): & \\
\hline \multirow[t]{2}{*}{ 300 300 ثانية } & $8 \times 90$ & 2 & 5 & 30 ثانية & 22.0 & $(8): ت$ & \\
\hline & & & & & المجموع 5. 56 & & \\
\hline 120 ثانية & $4 \times 120$ & 1 & 5 & 40/40 ثانية & 13.33 & (5) : & \multirow{4}{*}{ التدريبية الاولى التجريبية الثانية / الوحدة } \\
\hline 180+180/240 ثانية & $8 \times 120$ & 2 & 5 & 40 ثانية & 29.66 & $(8): ت$ & \\
\hline \multirow[t]{2}{*}{ 300 300 ثانية } & $4 \times 120$ & 1 & 5 & 40/40 ثانية & 16.33 & $(9): ت$ & \\
\hline & & & & & 59.32 & & \\
\hline 120 + 180 ثانية & $8 \times 90$ & 2 & 5 & 30 ثانية & 22.0 & $(10): ت$ & \multirow{4}{*}{ التدريبية الثانية التجريبية الاولى / الوحدة } \\
\hline 240 ثنانية & $4 \times 90$ & 1 & 5 & 30 ثانية & 12.5 & (12): & \\
\hline \multirow[t]{2}{*}{ 年 } & $8 \times 90$ & 2 & 5 & 30 ثانية & 22.0 & $(13): ت$ & \\
\hline & & 0 & 25 & & المجموع56.5 & & \\
\hline 180 + 120 120ثانية & $8 X 120$ & 2 & 5 & 40 ثنانية & 27.66 & ت: (10) & \multirow{4}{*}{ التدريبية الثانية التجريبية الثانية / الوحدة } \\
\hline 240 ثانية & $4 X 120$ & 1 & 5 & 40 ثانية & 15.33 & $(12): ت$ & \\
\hline \multirow[t]{2}{*}{ 300 ثانية } & $4 X 120$ & 1 & 5 & 40 ثانية & 16.33 & (13) : ت & \\
\hline & & 4 & 20 & 200 & المجموع 59.32 & & \\
\hline
\end{tabular}




\section{مفردات البرنامج التدريبي \\ الاسبوع : السابع}

الوحدة : الوحدة الاولى + الوحدة الثانية

\begin{tabular}{|c|c|c|c|c|c|c|c|}
\hline \multicolumn{2}{|c|}{ راحة بين } & \multirow{2}{*}{ المجاميع } & \multirow{2}{*}{ التكرارات } & \multirow{2}{*}{ زمن دوام المثير } & \multirow{2}{*}{ الزمن / دقيقة } & \multirow{2}{*}{ التمارين } & \multirow{2}{*}{ المجموعة التجريبية الاولى } \\
\hline مجموعة & تكرار & & & & & & \\
\hline 120 + 180 ثانية & $8 \times 90$ & 2 & 5 & 30 & 22.0 & (1) : & \multirow[t]{4}{*}{ الوحدة التجرييية الاولى } \\
\hline \multirow[t]{3}{*}{ 300 + 240 ثانية } & $8 \times 90$ & 2 & 5 & 30 & 26.0 & (2) : & \\
\hline & $4 \times 90$ & 1 & 5 & 30 ثانية & 8.5 & (3) : & \\
\hline & & 5 & 25 & ا 150 & المجموع 0. 56 & & \\
\hline 120 + 180 ثانية & $8 \times 120$ & 2 & 5 & 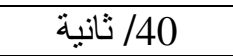 & 27.66 & (1) : & \multirow{4}{*}{ التدرييية الاولى التجريية الثانية / الوحدة } \\
\hline \multirow[t]{3}{*}{ انثانية } & $4 \times 120$ & 1 & 5 & 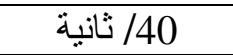 & 15.00 & (3) : & \\
\hline & $4 \times 120$ & 1 & 5 & ا ثانية & 11.33 & (4) & \\
\hline & & 4 & 20 & 200/ ثانية & 54.32 & & \\
\hline 120 ثانية & $4 \times 90$ & 1 & 5 & 30 ثانية & 10.5 & (2): ت & \multirow{4}{*}{ المجمو عة التجرييية الاولى / الوحدة } \\
\hline 180 + 180 & $8 \times 90$ & 2 & 5 & 30 & 25.66 & (7) $:$ ت & \\
\hline \multirow[t]{2}{*}{ 300/300 ثانية } & $8 \times 90$ & 2 & 5 & 30 & 23.66 & (6) & \\
\hline & & 5 & 25 & 150 & المجموع59.82 & & \\
\hline 120 ثانية & $4 X 120$ & 1 & 5 & 40 أثانية & 13.33 & ت: (2) & \multirow{4}{*}{ التدريبية الثانية التجريبيــة الثنانيــة / الوحـــة } \\
\hline \multirow[t]{3}{*}{180} & $8 X 120$ & 2 & 5 & |40/ ثانبة & 29.66 & (6) & \\
\hline & $4 X 120$ & 1 & 5 & ا 40/ ثانبة & 11.33 & (7) : & \\
\hline & & 4 & 20 & & المجموع 54.32 & & \\
\hline
\end{tabular}

